\title{
A comparative study of the viscoelastic constitutive models for frictionless contact interfaces in solids
}

\author{
Janete Alves $^{1}$, Nuno Peixinho ${ }^{1}$, Miguel Tavares da Silva ${ }^{2}$, Paulo Flores ${ }^{1, *}$ Hamid M. Lankarani $^{3}$ \\ ${ }^{1}$ Departamento de Engenharia Mecânica, Universidade do Minho, \\ Campus de Azurém, 4804-533 Guimarães, Portugal \\ ${ }^{2}$ Departamento de Engenharia Mecânica, Instituto Superior Técnico, Universidade de Lisboa \\ IST/IDMEC, Av. Rovisco Pais, 1, 1049-001 Lisboa, Portugal \\ ${ }^{3}$ Department of Mechanical Engineering, Wichita State University \\ Wichita, KS 67260-133, USA
}

\begin{abstract}
The nature of the constitutive contact force law utilized to describe contact-impact events in solid contact interfaces plays a key role in predicting the response of multibody mechanical systems and in the simulation of engineering applications. The goal of this work is to present a comparative study on the most relevant existing viscoelastic contact force models. In the sequel of this process, their fundamental characteristics are examined and their performances evaluated. Models developed based on the Hertz contact theory and augmented with a damping term to accommodate the dissipation of energy during the impact process, which typically is a function of the coefficient of restitution between the contacting solids, are considered in this study. In particular, the identified contact force models are compared in the present study for simple solid impact problems with the sole purpose of comparing the performance of the various models and examining the corresponding system behavior. The outcomes indicate that the prediction of the dynamic behavior of contacting solids strongly depends on the selection of the contact force model.
\end{abstract}

Keywords: Contact-impact events, Viscoelastic force models, Dynamic response

\section{Introduction}

The field of multibody systems dynamics has its roots in the classical methods of analytical dynamics and it develops to meet the growing demands in modeling, simulation and analysis of complex and advanced mechanical systems in military, industry, and engineering applications [1-4]. Multibody dynamics can be understood as the study of systems with multiple bodies whose interactions are affected by the application of external forces and by the presence of kinematic constraints [5-7]. In other words, a multibody system can be described as a collection of bodies acted upon by external forces and interconnected by kinematic pairs of different types that constrain their relative motion. The external actions applied on the system components may include gravitational and inertial forces, concentrated forces and statedependent forces in which contact-impact forces are included. In particular, contact-impact

\footnotetext{
*Corresponding author, Tel: + 351 253510220, Fax: +351 253516007, E-mail: pflores@dem.uminho.pt
} 
events occur very often in multibody systems [8-10]. As a result of an impact, the state of a system can change quite rapidly, resulting in discontinuities in the system velocities. Other effects related to the contact-impact phenomena are the vibration and load propagation to the system components and wear at the contact zone. Overall, the knowledge of the peak forces developed during the impact process is crucial for the dynamic analysis of mechanical systems and has consequences in the design process [11-13]. The subject of contact mechanics and its applications has received a great deal of attention over the last few decades, and still remains an active field of research and development [14-20]. There is no doubt that contact-impact events are ubiquitous in engineering and research activities, such as in railway dynamics [21-23], crashworthiness [24-26], robotics [27-29], biomechanics [30-32], mechanisms [33-35], and sound waves [36], to mention a few.

The establishment of a general criterion to group the different methods to deal with contact-impact events is not unanimous and simple. A general and broad embracing rule is to group them into contact force based methods (continuous methods) and the approaches based on the geometric constraints (piecewise methods) [37-39]. In a simple manner, three main features distinguish these two methods: $(i)$ the location of the contact points, $(i i)$ the relative penetration or indentation between contacting bodies, and (iii) the contact forces. In the contact force based methods, commonly referred to as penalty approaches, the location of the contact points does not coincide in both contacting bodies. With these methods a large number of potential contact points exist, in general, being the actual contact points those associated with the maximum indentation [40]. In turn, in the methods based on the geometric constraints, the contact points on both bodies are necessarily coincident due to the contact constraints imposed on the system. In these methods, the relative indentation between the contacting bodies is not permitted as bodies are considered to be entirely rigid at the contact zone [41]. In contrast, with the penalty approaches, relative indentation of bodies is allowed to occur, a reason for which these methods are also usually referred to as elastic approaches [42]. The indentation plays a crucial role as it is utilized to evaluate the contact forces according to an appropriate constitutive law [43]. The contact forces evaluated in this manner are equivalent to those that would appear if the contacting bodies were pressed against each other by an external static force [44]. On the other hand, in the geometric constraint methods, the contact forces are determined through the Lagrange multipliers associated with the reaction forces incorporated into the contact constraint equations [45].

The penalty approaches and their implementation, within the context of multibody dynamics with contact-impact, are computationally simple and efficient [46]. In these methods, the contact force is expressed as a continuous function of the indentation and indentation velocity of the contacting bodies. In this approach, there are no impulses at the instant of contact, and hence, there is no need for impulse dynamics calculations and the contact loss can easily be determined from the position and velocity data [47]. One of the main drawbacks associated with the penalty approach deals with the difficulty to choose the contact parameters that contribute to the evaluation of the contact force, such as the stiffness and damping of the contacting surfaces and the degree of nonlinearity of the indentation, especially for complex scenarios or nonmetallic materials [48, 49]. Another disadvantage of this formulation is that it can introduce highly-frequency dynamics into the system, due to the presence of stiff springs in compliant surfaces. Tracking the dynamics of such a system requires the integration algorithm to take very small steps, and consequently, the speed of simulation will be strongly penalized [50]. The normal contact force prevents penetration without any explicit kinematic constraint. In general, the stiffness and damping characteristics of the spring-damper elements are computed based on the relative indentation, material properties, surface geometries and kinematics of the contacting bodies. In the work by Khulief and Shabana [51] the required parameters for representing the contact force law were obtained based on the energy balance during the contact event. Lankarani and Nikravesh [52] presented two continuous contact force models for which the unknown parameters are evaluated analytically. In the first model, the internal damping of 
bodies represents the energy dissipation at low impact velocities. While in the second model, local plasticity of the surfaces in contact becomes the dominant source of energy dissipation. Dias and Pereira [53] described the contact law using a continuous force model based on the Hertz contact law augmented with a dissipative term that accounts for the effect of structural damping in flexible bodies.

An alternative technique to treat contact-impact problems in multibody systems is to use the Linear Complementarity Problem (LCP) [54]. Many researchers have considered the complementarity formulation associated with Moreau's time-stepping algorithm for contact modeling in multibody systems over the last years [55-57]. Assuming that the contacting bodies are truly rigid, as opposed to locally deformable bodies, as in the penalty approach, the complementarity formulation resolves the contact dynamics problem using unilateral constraints to compute contact impulses to prevent indentation from occurring. Thus, at the core of the LCP approach is an explicit formulation of the unilateral constraints between contacting bodies [5861]. One of the first published works on the complementarity problems is due to Signorini [62], who introduced an impenetrability condition in the form of a LCP. Later, Moreau [63] and Panagiotopoulos [64] also applied the concept of complementarity to study non-smooth dynamic systems. Pfeiffer and Glocker [54] extended the developments of Moreau and Panagiotopoulos to multibody dynamics with unilateral constraints, and the complementarity condition was considered of paramount importance. Indeed, complementarity approach proved to be quite useful to formulate many problems involving discontinuities [65-67].

Efficiently evolution of the contact-impact forces resulting from collisions in multibody systems requires that special attention be given to the numerical description of the constitutive laws used. Information on the impact velocities, material properties of the colliding bodies, and geometric characteristics of the contacting surfaces must be included into the contact force model. These characteristics are observed using a continuous contact force model, in which the local deformations and contact forces are considered as continuous functions. In dynamic simulations, it is quite important to find the precise instant of transition between the different states, namely the transition between non-contact and contact situations. If the initial contact instant is not detected properly, the initial contact force may become abnormally large due to an artificially large initial indentation between the contacting bodies. This numerical abnormality leads to an artificial increase in the system energy and, eventually, to the stall of the integration process when variable time step integration algorithms are utilized. To avoid this problem a close monitoring of the numerical procedure that systematically detects and analyzes all initial contact situations in an efficient manner is required. Otherwise, integration errors may buildup leading to meaningless results. In fact, most of the time consumed in modeling contact problems is spent on the contact detection task. This is crucial in multiple impact scenarios, such as railway multibody models and biomechanical contact situations. The dynamic study of this type of multibody systems may include hundreds of function evaluations of the candidate contact points, demanding fast and efficient methods to compute such interactions. Another relevant issue in contact-impact events deals with the development of general methodologies that allow for the accurate and efficient modeling and analysis of contact between freeform surfaces. A possible strategy consists of generating a preprocessing technique to prepare contact surfaces for dynamic contact simulations, keeping in memory only the part of the surface geometric information relevant to the actual contact state.

This paper extends previous authors' work [39] to present a complete and comparative study on several viscoelastic contact force approaches to model and simulate contact-impact events. This study begins with a brief overview of the main issues associated with contact mechanics, and then proceeds to analyze the fundamental characteristics of the most popular viscoelastic contact force models. In this process, the similarities and differences between the constitutive laws to evaluate contact forces are investigated. Results obtained from computational simulations and experiments of a single steel ball that impacts on cylindrical specimens are presented and utilized to discuss the main assumptions and limitations associated 
with the different contact force models analyzed. The engineering analysis and design implications of the obtained results can thus be observed.

\section{General issues in contact mechanics}

Undeniably, the classical problem of contact mechanics is quite an old topic in engineering applications [68-70]. According to Kozlov and Treshchev [71], the first investigation of impact goes back to 1668 and was carried out by Wren and Huygens. Newton later referred to the work of Wren in his former book "Mathematical Formulations of Natural Philosophy" published in 1687 [72]. Huygens performed studies on completely elastic collisions between two point masses and, besides conservations of momentum and kinetic energy, recognized the fact that the relative motion between two solids had to be taken into account in order to a universally valid law of impact could be formulated. Huygens law describing the relative velocities inversion during the elastic impact was extended by Newton through the inclusion of the coefficient of restitution in order to accommodate possible energy losses during the impact process.

One of the reasons for the success of classical impact theory is that it uses simple coefficients, namely the coefficient of restitution, to represent all the complex behavior that occurs at the contact-impact interface [73]. In fact, the contact mechanics approach offers the possibility of treating the contact region as a spring-damper system, making it possible to treat a contact-impact event as a continuous time dynamic phenomenon [74]. The mathematical description of the relation between force, indentation and time derivatives is referred to as constitutive equation of the material. Thus, in many engineering applications, the determination of the force-indentation relation and the coefficient of restitution are of paramount importance [75]. In particular, dynamic simulation of multibody systems requires reliable and accurate models to evaluate the contact forces at the contact-impact interfaces, as these have a strong influence on the simulation results. In dynamic simulations, contact forces are calculated from the indentation (pseudo-penetration) and indentation velocity during contact, which are determined at every time step from the state of the system. With the variation of the contact force during the contact period, the dynamic response of a system is obtained by updating these forces into the system's equations of motion. Since the equations of motion are integrated over the contact period, this approach results in a rather accurate system response even if changes in the system's configuration occur [76].

Among the possible contact scenarios that can be defined for the collision between two bodies that belong to a multibody system, the one-dimensional direct central contact between two solid spheres is considered here, due to its simplicity and straightforwardness, as the golden standard for this type of simulations and the ideal setting for the type of comparisons envisaged hereafter. When the spheres contact each other, deformation takes place in the local contact area resulting in a contact force. Two different phases can be distinguished during the contact process, namely the "compression", approaching or loading period and the "restitution", separating or unloading period [77]. The first phase starts when the two spheres come in contact and ends when the maximum deformation is reached. During this phase, the relative velocity of the contact points on the two bodies in the normal contact direction is gradually reduced to zero. The end of the compression phase is referred to as the instant of maximum compression or maximum approach, which corresponds to the maximum normal contact force if no dissipation of energy is considered. In turn, the restitution phase starts at this instant of time and ends when the two spheres separate from each other. During this phase, the bodies move away from one another while remaining in contact. In other words, during the compression phase the kinetic energy of relative motion is transformed into internal energy of deformation by the contact force, whilst during the subsequent phase of restitution, the elastic part of the internal energy is released. Elastic strain energy stored during compression generates the force that drives bodies apart during the restitution phase [78]. 
Depending on both the material properties of the contacting bodies and impact velocity, three main mechanisms may govern an impact event. An impact is said to be "elastic" or conservative when the indentation is completely reversible and independent of the indentation velocity and any consolidation time. In the case of a "viscoelastic" contact, the indentation is reversible, but the indentation itself shows a dependence on the indentation rate and a possible consolidation time. Finally, a "plastic" contact leaves an involved part permanently deformed. The deformation of a body in this case is independent of the indentation rate [79-81]. In the present study, only the two first mechanisms are considered, and the issue of plastic deformation is considered out of the scope of this work. The interested reader should refer the works by Yigit et al. [82], Thornton [83], Vu-Quoc et al. [84], and Wu et al. [85], for further details.

One of the most complex issues of modeling a contact-impact event is the process of energy dissipation. If an elastic body is subjected to cyclic load, the energy loss in the material causes a hysteresis loop in the force-indentation diagram [86]. The identification of damping parameters is often a complicated task as the dissipated energy within a mechanical system depends on the configuration of bodies, structural design and internal contact [87]. In the context of multibody dynamics, the total energy dissipation is, in general, controlled by the coefficient of restitution [88-90]. As stated by Seifried et al. [91], the coefficient of restitution is a joined term based on different processes of kinetic energy loss such as viscoelastic material behavior, heat generation, and wave propagation in the contacting bodies [92]. The coefficient of restitution is a dimensionless and statistical parameter that varies between 0 and 1 , where 0 corresponds to a totally inelastic impact and 1 to a perfectly elastic impact [93]. The coefficient of restitution is not an intrinsic material property. It depends on the materials of the contacting bodies, their surface geometry, impact velocity and temperature. The major advantage of the coefficient of restitution concept is its simplicity. The simple algebraic relation between velocities before and after impact makes it easy to determine the velocities after impact. Determining its value accurately requires experimental work in general [94].

\section{Comparative study of dissipative contact force models}

The contact process between two solid spherical bodies can be represented as a spring and a damper, as illustrated in Fig. 1. In the most general form, the contact force can be written in terms of its elastic (conservative) and viscous (dissipative) components as follows [39]

$$
f=K \delta^{n}+\chi \delta^{m} \dot{\delta}
$$

where $K$ represented the generalized contact stiffness, $\chi$ denotes the hysteresis damping factor, $\delta$ the relative indentation of the contacting spheres, and $\dot{\delta}$ the indentation velocity. Such a power relation is said to be Hookeian (when $n=1$ ) or Hertzian (when $n=3 / 2$ ); it can present a discontinuity on initial contact (when $m=0$ ) or it can have the damping term weighted by the elastic force (when $m=n$ ). Oden and Martins [95] discussed the energy loss obtained with this contact force approach. Over the last few decades, several different authors have determined the values of $m$ and $\chi$ based both on theoretical and experimental approaches, being the Hunt and Crossley work one of the most relevant in this field [96].

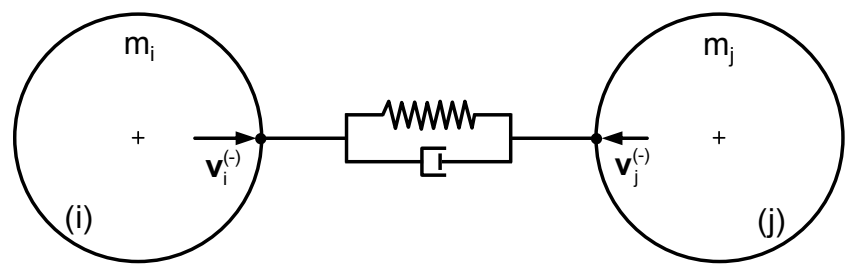

Fig. 1 Representation of the normal contact action between two solid spherical bodies. 
In order to ensure that the energy dissipated during the contact process is consistent with the energy loss subsumed in the coefficient of restitution, several researchers have proposed approximated and exact relations for $\chi$ and the coefficient of restitution. The Hunt and Crossley contact force model is considered by many researchers to be the most significant progress of compliant contact force modeling, due to its ability to overcome the weaknesses of the purely elastic approaches, great simplicity and easiness of its implementation in any general code [9799]. Much of the research based on the Hunt and Crossley nonlinear force contact model has revolved around the issue of how to determine the hysteresis damping factor, $\chi$, and more particularly, on how it can be expressed as a function of the coefficient of restitution. The resulting methods developed to evaluate the hysteresis damping factor can be categorized into two main groups [16]. The first category is described as the energy-based approaches, in which the work-energy principle is considered to obtain the expression for the hysteresis damping factor. The models proposed by Hunt and Crossley [96], Lankarani and Nikravesh [100], and Flores et al. [101] are examples of the energy-based formulation. In the second category, the equations of motion are addressed directly and include an approximate solution, such as the Herbert and McWhannell approach [102], as well as the exact solution [103]. From the practical point of view, the different models to derive the hysteresis damping factor may result in significant differences in the impact response.

Over the last decades several different constitutive laws for contact-impact events have been suggested mostly based on the prominent one proposed by Hertz. Because this model is purely elastic in nature, it cannot describe the energy loss during the contact process. Thus, other contact force models have been presented that augment the Hertzian law with damping terms that accommodate the energy loss. In what follows, the main viscoelastic contact force models are presented and after that comparative study is commented. The Hertz law relates the contact force with a nonlinear power function of the penetration and it is expressed as [104]

$$
f=K \delta^{n}
$$

where $K$ is a contact stiffness and $\delta$ represents the relative pseudo-penetration or indentation. According to the Hertzian contact approach, the power exponent $n$ is equal to $3 / 2$ for the case where there is a parabolic distribution of contact stresses [68]. For different materials, the value of this exponent can be either higher or lower, leading to a convenient contact force expression based on experimental data, but that should not be confused with the Hertzian contact theory. For two spheres in contact, the contact stiffness is a function of the radii of the spheres $i$ and $j$ and the material properties as follows

$$
K=\frac{4}{3\left(\sigma_{i}+\sigma_{j}\right)} \sqrt{\frac{R_{i} R_{j}}{R_{i}+R_{j}}}
$$

in which the material parameters $\sigma_{i}$ and $\sigma_{j}$ are given by

$$
\sigma_{k}=\frac{1-v_{k}^{2}}{E_{k}}, \quad(k=i, j)
$$

and the quantities $v_{k}$ and $E_{k}$ are, respectively the Poisson's ratio and theYoung's modulus of elasticity associated with each sphere. Hunt and Crossley [96] represented the contact force model using the Hertz law together with a nonlinear viscoelastic element as

$$
f=K \delta^{n}+D \dot{\delta}
$$

where the first term of the right-hand side is referred to as the elastic force and the second term accounts for the energy dissipated during the contact process. In Eq. (5), $D$ denotes the damping coefficient, which is defined as [96] 


$$
D=\chi \delta^{n}
$$

in which $\chi$ is the so-called "hysteresis damping factor". In the model of Eq. (5), tension force in the contact period is avoided as long as $0 \leq K \leq \chi \dot{\delta}$.

Over the last decades several formulations for the hysteresis damping factor have been proposed, which are typically functions of the contact stiffness, initial contact velocity and coefficient of restitution. Table 1 summarizes some of the most popular expressions for the hysteresis damping factor that have been developed independently by different authors.

Table 1 Hysteresis damping factors for different viscoelastic models, in Eq. (1).

\begin{tabular}{|c|c|c|c|c|}
\hline Contact force model & Constitutive law & $n$ & $m$ & $\chi$ \\
\hline Hertz [104] & $f=K \delta^{\frac{3}{2}}$ & $3 / 2$ & - & - \\
\hline Anagnostopoulos [105] & $f=K \delta+\chi \delta \dot{\delta}$ & 1 & 1 & $\chi=2 \frac{-\ln c_{r}}{\sqrt{\pi^{2}+\left(\ln c_{r}\right)^{2}}} \sqrt{K m_{e f f}}$ \\
\hline $\begin{array}{l}\text { Ristow [106] } \\
\text { Shäfer et al. [107] }\end{array}$ & $f=K \delta^{\frac{3}{2}}+\chi \delta \dot{\delta}$ & $3 / 2$ & 1 & Empirical \\
\hline Lee and Herrmann [108] & $f=K \delta^{\frac{3}{2}}+m_{e f f} \chi \delta \dot{\delta}$ & $3 / 2$ & 1 & Empirical \\
\hline $\begin{array}{l}\text { Hunt and Crossley [96] } \\
\text { Marefka and Orin [27] }\end{array}$ & $f=K \delta^{\frac{3}{2}}+\chi \delta^{\frac{3}{2}} \dot{\delta}$ & $3 / 2$ & $3 / 2$ & $\chi=\frac{3\left(1-c_{r}\right)}{2} \frac{K}{\dot{\delta}^{(-)}}$ \\
\hline Herbert and McWhannell [102] & $f=K \delta^{\frac{3}{2}}+\chi \delta^{\frac{3}{2}} \dot{\delta}$ & $3 / 2$ & $3 / 2$ & $\chi=\frac{6\left(1-c_{r}\right)}{\left[\left(2 c_{r}-1\right)^{2}+3\right]} \frac{K}{\dot{\delta}^{(-)}}$ \\
\hline Lee and Wang [109] & $f=K \delta^{\frac{3}{2}}+\chi \delta^{\frac{3}{2}} \dot{\delta}$ & $3 / 2$ & $3 / 2$ & $\chi=\frac{3\left(1-c_{r}\right)}{4} \frac{K}{\dot{\delta}^{(-)}}$ \\
\hline Lankarani and Nikravesh [100] & $f=K \delta^{\frac{3}{2}}+\chi \delta^{\frac{3}{2}} \dot{\delta}$ & $3 / 2$ & $3 / 2$ & $\chi=\frac{3\left(1-c_{r}^{2}\right)}{4} \frac{K}{\dot{\delta}^{(-)}}$ \\
\hline $\begin{array}{l}\text { Gonthier et al. [110] } \\
\text { Zhang and Sharf [103] }\end{array}$ & $f=K \delta^{\frac{3}{2}}+\chi \delta^{\frac{3}{2}} \dot{\delta}$ & $3 / 2$ & $3 / 2$ & $\chi \approx \frac{1-c_{r}^{2}}{c_{r}} \frac{K}{\dot{\delta}^{(-)}}$ \\
\hline Zhiying and Qishao [111] & $f=K \delta^{\frac{3}{2}}+\chi \delta^{\frac{3}{2}} \dot{\delta}$ & $3 / 2$ & $3 / 2$ & $\chi=\frac{3\left(1-c_{r}^{2}\right) e^{2\left(1-c_{r}\right)}}{4} \frac{K}{\dot{\delta}^{(-)}}$ \\
\hline Flores et al. [101] & $f=K \delta^{\frac{3}{2}}+\chi \delta^{\frac{3}{2}} \dot{\delta}$ & $3 / 2$ & $3 / 2$ & $\chi=\frac{8\left(1-c_{r}\right)}{5 c_{r}} \frac{K}{\dot{\delta}^{(-)}}$ \\
\hline Gharib and Hurmuzlu [112] & $f=K \delta^{\frac{3}{2}}+\chi \delta^{\frac{3}{2}} \dot{\delta}$ & $3 / 2$ & $3 / 2$ & $\chi=\frac{1}{c_{r}} \frac{K}{\dot{\delta}^{(-)}}$ \\
\hline $\begin{array}{l}\text { Kuwabara and Kono }[113] \\
\text { Brilliantov et al. }[114,115]\end{array}$ & $f=K \delta^{\frac{3}{2}}+\chi \delta^{\frac{1}{2}} \dot{\delta}$ & $3 / 2$ & $1 / 2$ & $\chi=\frac{K}{3} \frac{\left(3 \eta_{2}-\eta_{1}\right)^{2}}{3 \eta_{2}+2 \eta_{1}} \frac{(1-v)(1-2 v)}{E v^{2}}$ \\
\hline Tsuji et al. [116] & $f=K \delta^{\frac{3}{2}}+\chi \delta^{\frac{1}{4}} \dot{\delta}$ & $3 / 2$ & $1 / 4$ & $\chi=\alpha \sqrt{K m_{e f f}}$ \\
\hline Jankowski [117] & $\begin{array}{l}f=K \delta^{\frac{3}{2}}+\chi \delta \dot{\delta},(\dot{\delta}>0) \\
f=K \delta^{\frac{3}{2}},(\dot{\delta}<0)\end{array}$ & $3 / 2$ & 1 & $\chi=2 \frac{9 \sqrt{5}}{2} \frac{1-c_{r}^{2}}{c_{r}\left[c_{r}(9 \pi-16)+16\right]} \sqrt{K \delta^{\frac{1}{2}} m_{e f f}}$ \\
\hline $\begin{array}{l}\text { Bordbar and Hyppänen [118] } \\
\text { Schwager and Poschel [119] }\end{array}$ & $f=K \delta^{\frac{3}{2}}+\chi \delta^{0.65} \dot{\delta}$ & $3 / 2$ & 0.65 & Empirical \\
\hline
\end{tabular}

From the analysis of Table 1, it can be observed that there are several different approaches to accommodate the energy dissipation in contact events by means of the hysteresis damping factor. In some cases, the dissipative term is dependent on empirical parameters that characterize the contact zone, namely in the models proposed by Kuwabara and Kono [113], Tsuji et al. [116], and Bordbar and Hyppänen [118]. Other approaches exhibit discontinuities in 
the contact force evolution [117], and problems of consistency of units [119]. There are, however, a set of models where the hysteresis damping factor is expressed in terms of the local contact properties, contact geometry and contact kinematics, making them appropriate for multibody dynamics simulations [27, 96, 100-103, 109-112].

The Kelvin-Voigt linear dissipative force model [68] has an analytic solution that leads to a constant coefficient of restitution independently of the initial impact velocity, which is not consistent with experiments [120]. Besides of these limitations, this linear model has been widely utilized [51, 121-124]. The limitations of a constant coefficient of restitution and a constant contact duration can be overcome by considering nonlinear spring damper elements. Based on the Hertzian contact theory, several constitutive force laws have been developed extending the original approach by Hertz. Most of these modified models lead to differential equations of motion with no analytical solution. Ristow [106], Shäfer et al. [107] and Lee and Herrmann [108] proposed partly nonlinear models that had similar weakness as the KelvinVoigt approach, because the dissipative force component is still linearly dependent on the deformation rate. Kuwabara and Kono [113] proposed a fully nonlinear model. This model was independently derived by Brilliantov et al. [114, 115] revealing an hysteresis damping factor as a material property obtained from bulk viscosities of the materials involved in the contact. Due to the lack of information on the bulk viscosities, the dissipative damping factor was treated as an adjustable parameter by Brilliantov et al. [114]. This force model leads to a coefficient of restitution that decreases with the increasing of impact velocity, in agreement with experiments [120]. Tsuji et al. [116] proposed a Hertzian-type force law including a slightly modified dissipative term with a different exponent. This model leads to a constant coefficient of restitution.

Hertz-type contact force models describe a nonlinear relation between the normal contact force and local deformation, in terms of the material properties of the contact bodies and local contact surface geometries. There are several advantages to the Hertzian contact models. First, they precisely take into account the surface geometry, which may be the most important factor affecting the contact response. Second, these models can easily incorporate friction effects. Their weaknesses are the requirements of a very precise contact detection algorithm, uncertainty in the determination of contact parameters, and small integration step sizes during simulation. In particular, the identification of the damping parameters is often a complicated task as the dissipated energy, within a mechanical system, depends on the configuration of materials, structural design and internal contact $[125,126]$. Damping, in contact problems, is often a joint term, which covers several effects like internal heating, viscoelastic effects, plastic deformation and the propagation of elastic waves during impact [91].

As it was mentioned above, much of the research based on the Hunt and Crossley model revolved around the issue of how to determine the hysteresis damping factor, and more precisely, how it can be expressed as function of the coefficient of restitution. The approaches available in the literature that consider the evaluation of the damping term can be categorized into two main groups. The first group holds those described as the energy-based approaches, such as the Hunt and Crossley [96], and Lankarani and Nikravesh [100]: these models are characterized by the application of the work-energy principle in the derivation of the hysteresis damping term. The second group that includes methods that directly tackle the equation of motion based on Eq. (5) and include the approximate solutions by Herbert and McWhannell [102] and Lee and Wang [109], or the exact solution by Zhang and Sharf [103] and Gonthier et al. [110]. From the analytical stand point, all approaches for the calculation of the hysteresis damping factor appear reasonable. From the practical view point, the different models for the hysteresis damping factor may result in significant differences in the impact response [127129]. For the sole purpose of analyzing the response of the most relevant contact force models, the behavior of the hysteresis damping factor is evaluated for different values of the coefficient of restitution. In order to keep this analysis simple, only hysteresis damping factor expressions that explicitly depend on the initial impact velocity are utilized. These are, in fact, the most 
common contact force approaches used for contact modeling and simulation in the context of multibody mechanical systems [130-135]. In addition, the ratio between contact stiffness and initial impact velocity is considered to be equal to unity. Figure 2 shows the plots of the hysteresis damping factor as a function of the coefficient of restitution for different contact approaches.

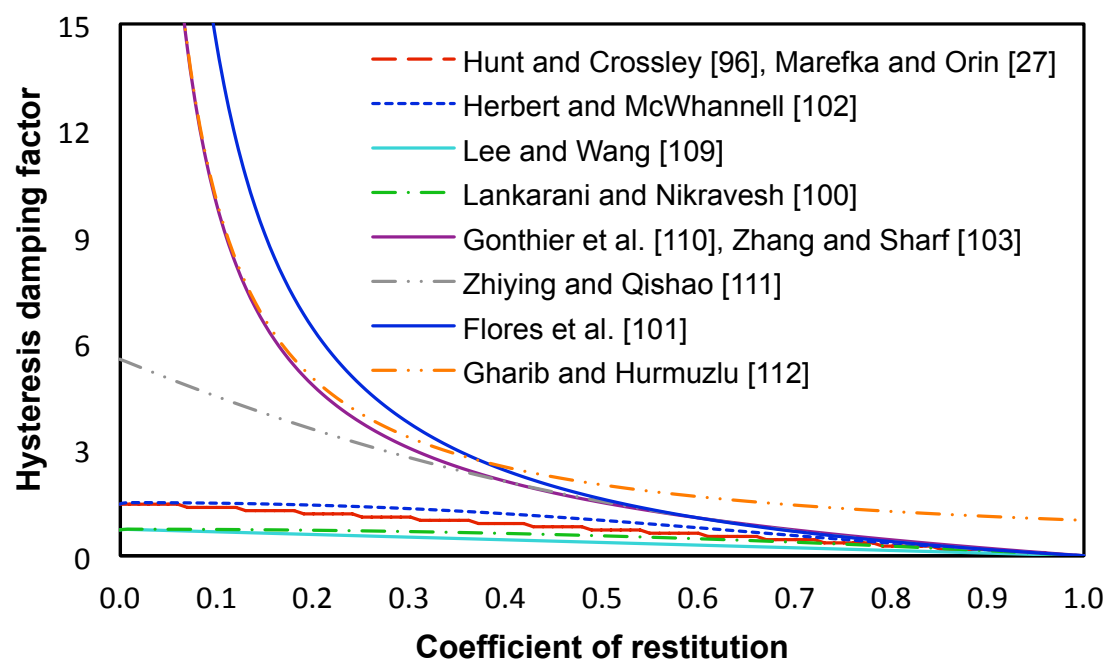

Fig. 2 Resulting hysteresis damping factor as function of the coefficient of restitution for different dissipative contact force models.

From Fig. 2, it can be observed that all the models considered in the present analysis, except the one proposed by Gharib and Hurmuzlu [112], exhibit a similar response when the value of the coefficient of restitution is higher than 0.7. In fact, most of the available contact force models have been proposed for nearly elastic contacts, not responding adequately for reduced values of the coefficient of restitution, as it is observed in the plots of Fig. 2 in the cases of Hunt and Crossley [96], Marefka and Orin [27], Herbert and McWhannell [103], Lee and Wang [109] and Lankarani and Nikravesh [100]. In particular, the model by Lee and Wang is the one that dissipates the least amount of energy during the impact event. In turn, the contact force approaches by Gonthier et al. [110], Zhang and Sharf [103], Zhiying and Qishao [111] and Flores et al. [101] present a similar behavior for moderate coefficient of restitution values. This is true for coefficients of restitution higher than 0.5 , as it can be observed in the diagrams plotted of Fig. 2. For the case of low values of the coefficient of restitution, the models by Gonthier et al. [110], Zhang and Sharf [103], Flores et al. [101] and Gharib and Hurmuzlu [112] present a close behavior. For these models, the hysteresis damping factor increases asymptotically with the decrease of the coefficient of restitution, meaning that they can perform satisfactorily for perfectly inelastic contacts.

It must be pointed out that the contact force models analyzed in this study do only hold if viscoelasticity is not the only dissipative process during the contact event. For the cases where friction, plastic deformation, brittle failure, fracture, adhesion, among other effects, have to be considered, there are more appropriate models to simulate the bodies in contact [136-146].

\section{Comparative study using numerical simulations}

In order to better understand what the consequences of using different constitutive laws for modeling contact events are, the direct-central impact of two aluminum spheres, illustrated in Fig. 1, is considered here as a first application example [68]. The spheres are identical and have the same radius of $20 \mathrm{~mm}$ and the same mass of $0.092 \mathrm{~kg}$. Both spheres have equal and opposite impact velocities of $0.15 \mathrm{~m} / \mathrm{s}$. A relative contact stiffness of $5.5 \times 10^{9} \mathrm{~N} / \mathrm{m}^{3 / 2}$ and a coefficient of restitution equal 0.7 have been considered for the calculations [39, 42, 52]. The comparative behavior of the different contact force models considered is quantified by 
plotting the contact force versus indentation and the phase portrait. The relative indentation and the indentation velocity are the variables used to generate the phase portrait plots.

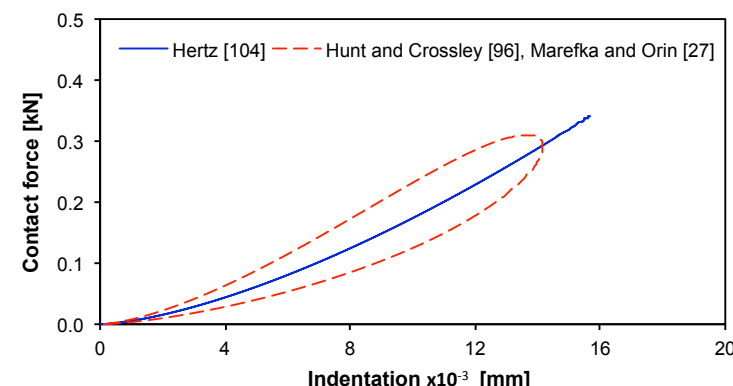

(a)

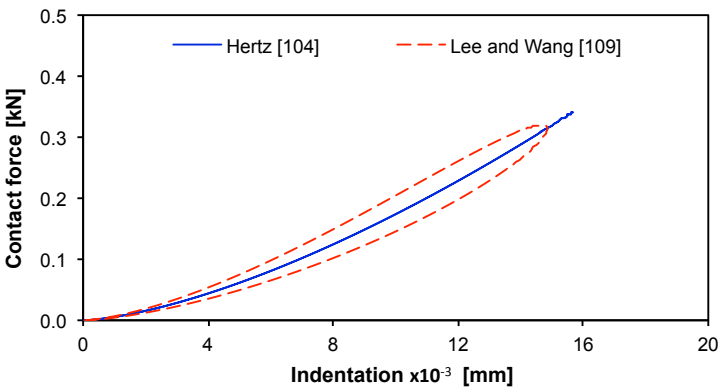

(c)

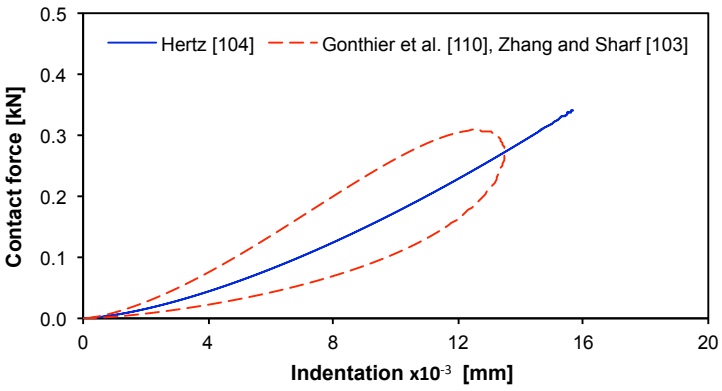

(e)

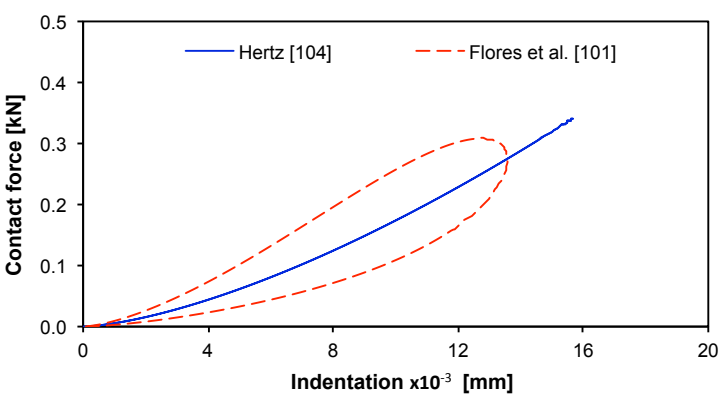

(g)

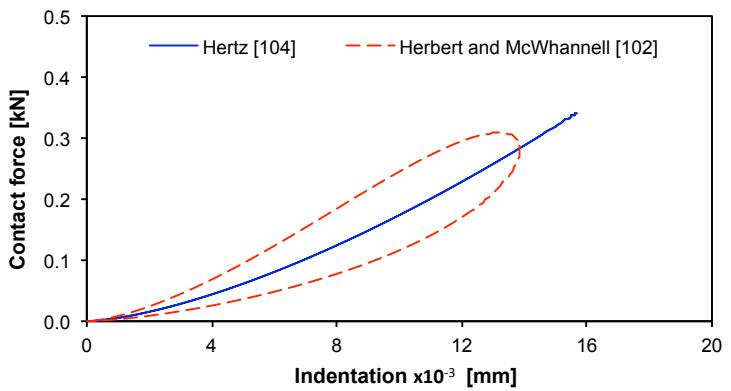

(b)

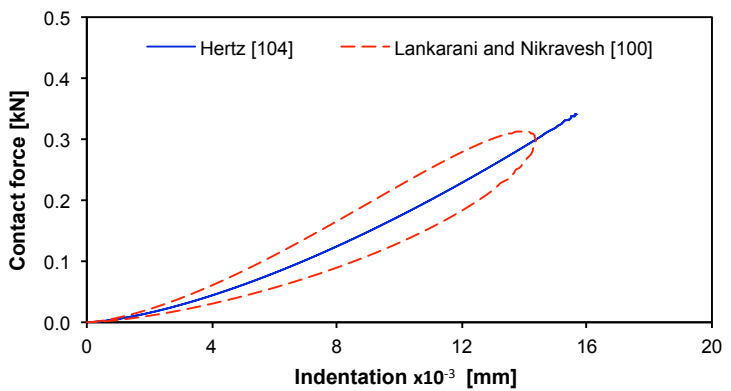

(d)

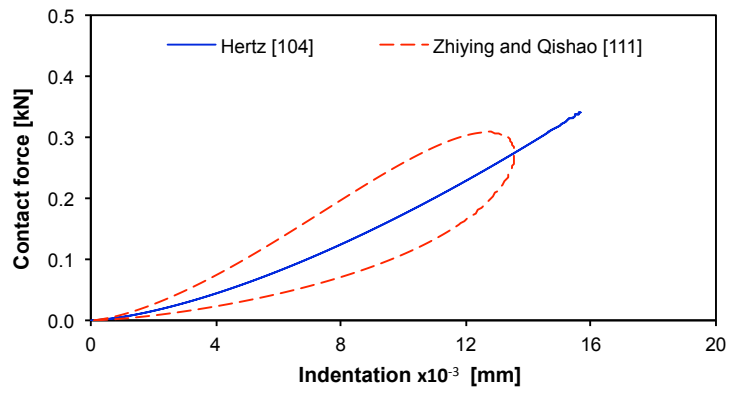

(f)

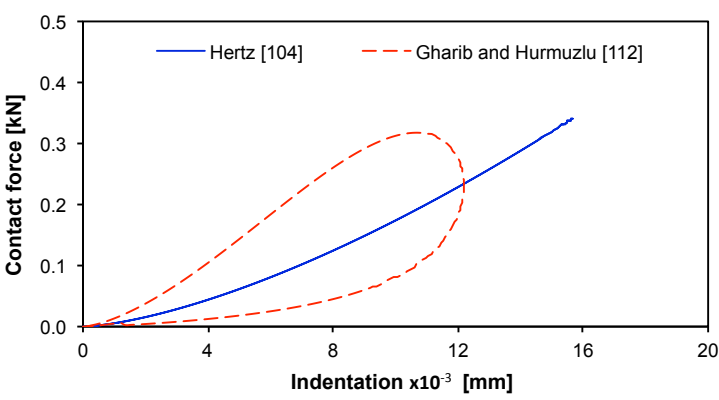

(h)

Fig. 3 Force-indentation relation for different contact force models for a direct-central impact of two spheres: (a) Hunt and Crossley, Marefka and Orin; (b) Herbert and McWhannell; (c) Lee and Wang; (d) Lankarani and Nikravesh; (e) Gonthier et al., Zhang and Sharf; (f) Zhiying and Qishao; (g) Flores et al.; (h) Gharib and Hurmuzlu.

Figure 3 shows the force-indentation relation for different contact force models, namely those considered in the previous section. It is clear that the energy dissipated during the contact process is associated with the hysteresis loop of the force-indentation diagrams. It can be observed that the Lee and Wang model dissipates less amount of energy, visible in the smallest area within the hysteresis loop. In fact, the Lee and Wang force model is the most elastic among all the presented approaches. In sharp contrast, the model recently proposed by Gharib and Hurmuzlu is the most dissipative contact force model. This fact is not surprising in the measure that this approach has been characterized to be very inelastic in nature [112]. The behavior of the remaining contact force models can be categorized into two main groups. The first group 
includes the Hunt and Crossley, Marefka and Orin, and Lankarani and Nikravesh models, since they exhibit a very similar response in terms of the hysteresis loop. The second group incorporates the contact force models by Herbert and McWhannell, Gonthier et al., Zhang and Sharf, Zhiying and Qishao, and Flores et al. These force models present a similar hysteresis loop for moderate or high values of the coefficient of restitution. It must be highlighted that for all the models, the contact force varies in a nonlinear and continuous manner and it stars form zero and returns to zero while always remains compressive.

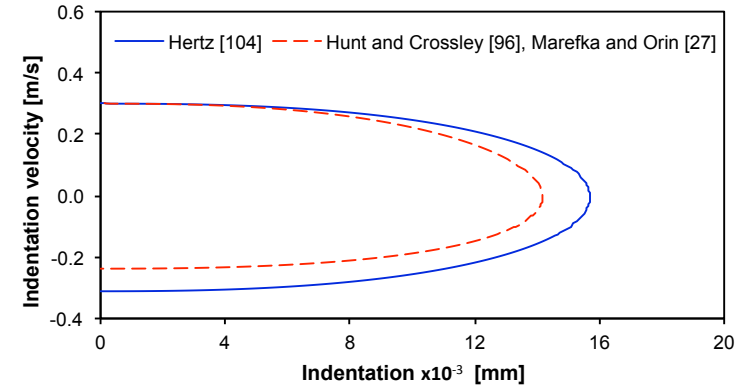

(a)

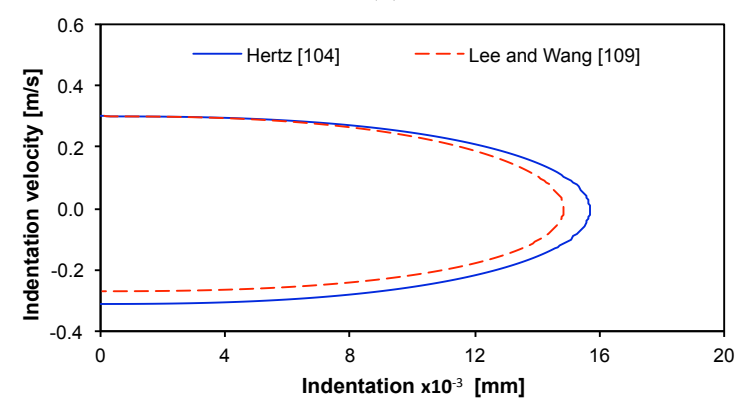

(c)

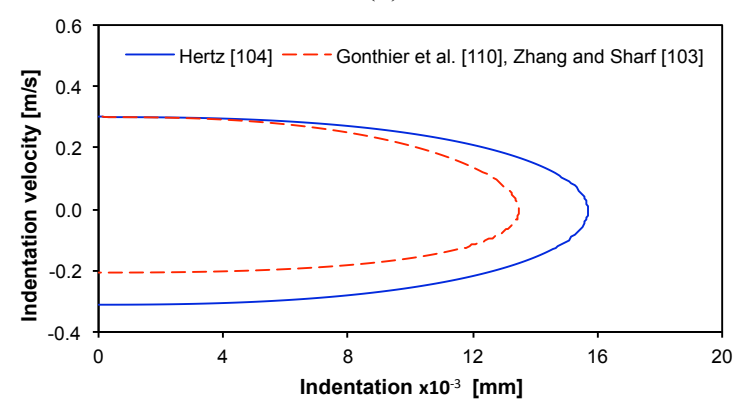

(e)

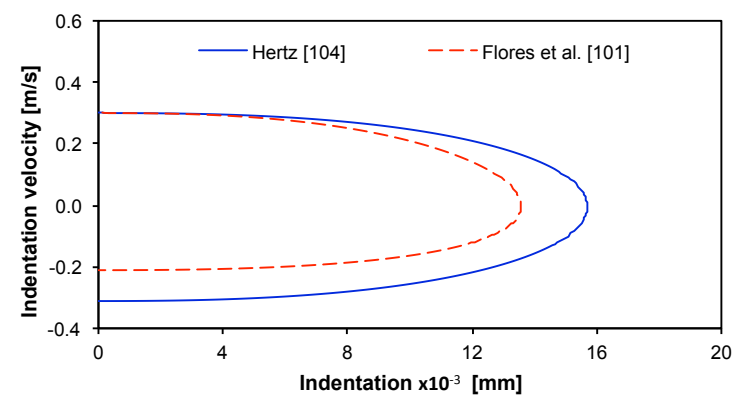

(g)

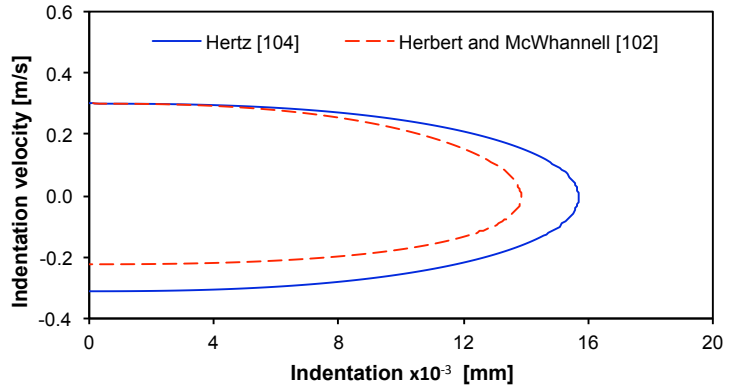

(b)

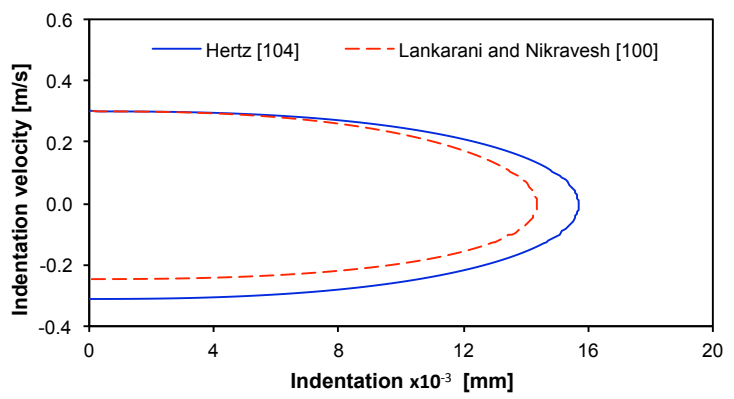

(d)

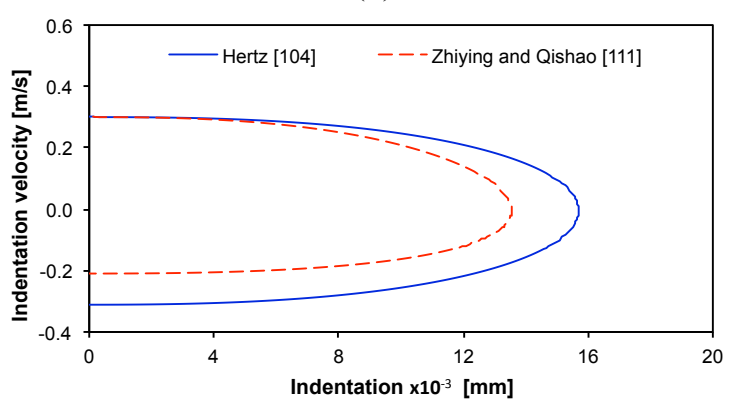

(f)

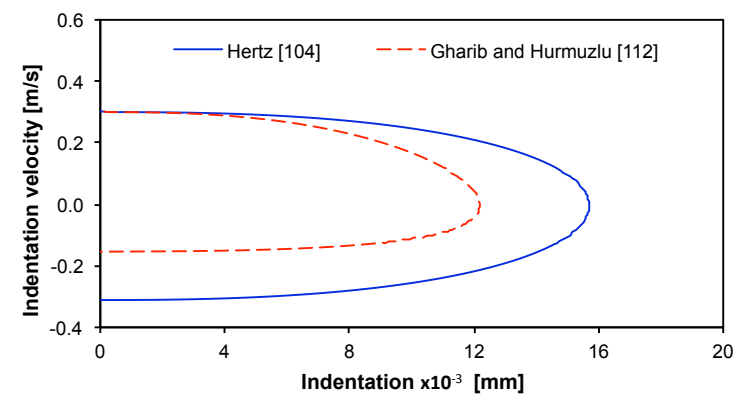

(h)

Fig. 4 Phase portraits for different contact force models for a direct-central impact of two spheres: (a) Hunt and Crossley, Marefka and Orin; (b) Herbert and McWhannell; (c) Lee and Wang; (d) Lankarani and Nikravesh; (e) Gonthier et al., Zhang and Sharf; (f) Zhiying and Qishao; (g) Flores et al.; (h) Gharib and Hurmuzlu.

A similar comparison and discussion on the different contact force models can be performed by analyzing the plots of Fig. 4 relative to the phase portraits of the direct-central impact of two spheres. Figure 4 shows the phase trajectories of the impact process, in which the 
point that corresponds to null indentation and $0.3 \mathrm{~m} / \mathrm{s}$ velocity represents the initial instant of impact. Then the positive side of the plot denotes the compression phase of the contact that ends at point in which the impact velocity is null and the relative indentation reaches its maximum. In turn, the negative part of the curves corresponds to the restitution phase of the contact process and, for the case of Hertz model, the post-impact velocity is equal to $-0.3 \mathrm{~m} / \mathrm{s}$. For the dissipative force models presented, the amount of energy loss during the impact is related to the lower values of the post-impact velocity. Again for the most dissipative approach, the postimpact velocity presents the lowest value, namely for the Gharib and Hurmuzlu model. Finally, the force models proposed by Herbert and McWhannell, Gonthier et al., Zhang and Sharf, Zhiying and Qishao, and Flores et al. exhibit a similar behavior with a post-impact velocity value equal to $-0.2 \mathrm{~m} / \mathrm{s}$.

In what follows, experimental data obtained for a classical ball impact on a massive surface are presented and utilized to compare some of the contact force models studied earlier. For this purpose, the experimental methodology produced by Zhang and Sharf [16] is considered. A schematic representation of the impact scenario is illustrated in Fig. 5, which consists of an external impact between a steel ball and a steel cylindrical specimen. The cylindrical specimen is considered to be stationary. The diameter and mass of the ball are equal to $0.54 \mathrm{~kg}$ and $5.08 \mathrm{~cm}$, respectively. In turn, the diameter and thickness of the cylindrical specimens are both equal to $5.08 \mathrm{~cm}$. An accelerometer is attached to the steel ball, as represented in Fig. 5.

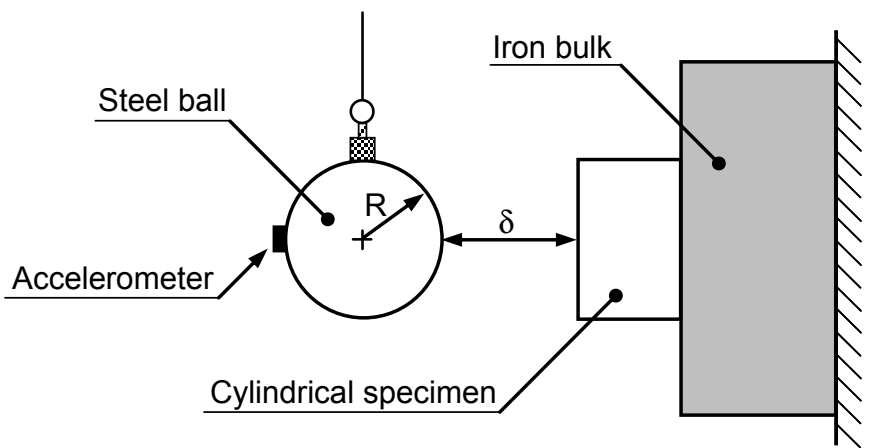

Fig. 5 Impact between a steel ball and a cylindrical specimen \{Adapted from [16]\}.

The basic idea of this experimental apparatus is to simulate a free ball impacting a massive and stationary surface [68]. With the approach described by Zhang and Sharf [16], it is possible to determine the contact forces for different initial heights of the steel ball and for several impact velocities. This model is utilized here to study contacts at low impact velocities, that is, less than $0.5 \mathrm{~m} / \mathrm{s}$. For each experiment, the steel ball was released from different initial positions and the acceleration profile was obtained during the contact process. Then the contact force was obtained by applying the Newton's second law $(F=m a)$ [5]. Table 2 lists the properties of the contacting parts. Two different materials for the cylindrical specimens are considered and designated as $\mathrm{C} 1$ and $\mathrm{C} 2$ [16]. The yielding contact force, also listed in Table 2, represents the value of the contact force at which the material initiates plastic deformation. It should be highlighted that a force transducer was not used to directly measure the contact force. The reason for this was that the accelerometers are typically much smaller and lighter than force transducers, and hence do not add any significant mass to the system. Furthermore, filtering has been done on all the experimental signals according to the standard SAE J211. All the experimental data were taken from the source [16].

Table 2 Properties of the contacting bodies utilized in the present work AAdapted from [16]\}.

\begin{tabular}{|c|c|c|c|}
\hline Contact part & $\begin{array}{c}\text { Young's modulus } \\
{[\mathrm{GPa}]}\end{array}$ & Poisson's ratio & $\begin{array}{c}\text { Contact force of } \\
\text { yield }[\mathrm{N}]\end{array}$ \\
\hline Steel ball & 210 & 0.30 & - \\
\hline
\end{tabular}




\begin{tabular}{|l|c|c|c|}
\hline Specimen C1 & 213 & 0.29 & 6674 \\
\hline Specimen C2 & 205 & 0.29 & 42 \\
\hline
\end{tabular}

Table 3 Generalized contact stiffness and coefficient of restitution \{Adapted from [16]\}.

\begin{tabular}{|c|c|c|}
\hline Contact part & $\begin{array}{c}\text { Contact stiffness } \\
{\left[\mathrm{N} / \mathrm{m}^{3 / 2}\right]}\end{array}$ & $\begin{array}{c}\text { Coefficient of } \\
\text { restitution }\end{array}$ \\
\hline Specimen $\mathrm{C} 1(0.094 \mathrm{~m} / \mathrm{s})$ & $2.46 \times 10^{10}$ & 0.974 \\
\hline Specimen $\mathrm{C} 1(0.500 \mathrm{~m} / \mathrm{s})$ & $2.46 \times 10^{10}$ & 0.955 \\
\hline Specimen $\mathrm{C} 2(0.094 \mathrm{~m} / \mathrm{s})$ & $2.41 \times 10^{10}$ & 0.917 \\
\hline Specimen C2 $(0.500 \mathrm{~m} / \mathrm{s})$ & $2.41 \times 10^{10}$ & 0.757 \\
\hline
\end{tabular}

The analysis and interpretation of the results obtained from computational simulations using the different contact force models described above are presented in the following paragraphs. The computational results are compared with the experimental data. The test scenario corresponds to the situation described above relative to the impact between a free steel ball and a massive solid. Two different initial impact velocities are considered, namely $0.094 \mathrm{~m} / \mathrm{s}$ and $0.500 \mathrm{~m} / \mathrm{s}$ that represent collisions at "low" and "moderate" impact velocities. Table 3 presents the contact properties in terms of relative contact stiffness and coefficient of restitution, for both impact velocities, and for the cylindrical specimens $\mathrm{C} 1$ and $\mathrm{C} 2$. Because the values of the coefficient of restitution are relatively high, in what follows, the contact force model proposed by Gharib and Hurmuzlu has been omitted, since this approach is mainly valid for low values of the coefficient of restitution.

Table 4 Global results obtained in terms of maximum contact force and corresponding percentage error.

\begin{tabular}{|c|c|c|c|c|c|c|c|c|}
\hline \multirow{3}{*}{$\begin{array}{l}\text { Contact force } \\
\text { model }\end{array}$} & \multicolumn{2}{|c|}{ Specimen C1 } & \multicolumn{2}{|c|}{ Specimen C1 } & \multicolumn{2}{|c|}{ Specimen C2 } & \multicolumn{2}{|c|}{ Specimen C2 } \\
\hline & \multicolumn{2}{|l|}{$0.094 \mathrm{~m} / \mathrm{s}$} & \multicolumn{2}{|l|}{$0.500 \mathrm{~m} / \mathrm{s}$} & \multicolumn{2}{|l|}{$0.094 \mathrm{~m} / \mathrm{s}$} & \multicolumn{2}{|c|}{$0.500 \mathrm{~m} / \mathrm{s}$} \\
\hline & $\mathrm{F}_{\max }[\mathrm{N}]$ & Error [\%] & $\mathrm{F}_{\max }[\mathrm{N}]$ & Error [\%] & $\mathrm{F}_{\max }[\mathrm{N}]$ & Error [\%] & $\mathrm{F}_{\max }[\mathrm{N}]$ & Error $[\%]$ \\
\hline Experimental [16] & 663.0 & - & 4709.6 & - & 660.2 & - & 4364.6 & - \\
\hline Hertz [104] & 662.5 & -0.1 & 4937.8 & 4.8 & 657.5 & -0.4 & 4899.9 & 12.3 \\
\hline $\begin{array}{l}\text { Hunt and Crossley [96], } \\
\text { Marhefka and Orin [27] }\end{array}$ & 652.7 & -1.6 & 4817.6 & 2.3 & 630.6 & -4.5 & 4496.4 & 3.0 \\
\hline Herbert and McWhannell [102] & 652.4 & -1.6 & 4812.8 & 2.2 & 628.9 & -4.7 & 4464.1 & 2.3 \\
\hline Lee and Wang [109] & 657.4 & -0.8 & 4874.3 & 3.5 & 642.6 & -2.7 & 4633.5 & 6.2 \\
\hline Lankarani and Nikravesh [100] & 652.8 & -1.5 & 4820.0 & 2.3 & 631.5 & -4.3 & 4522.3 & 3.6 \\
\hline $\begin{array}{l}\text { Gonthier et al. [110], Zhang } \\
\text { and Sharf [103] }\end{array}$ & 649.5 & -2.0 & 4780.2 & 1.5 & 622.9 & -5.7 & 4436.0 & 1.6 \\
\hline Zhying and Qishao [111] & 652.3 & -1.6 & 4810.1 & 2.1 & 627.8 & -4.9 & 4444.0 & 1.8 \\
\hline Flores et al. [101] & 651.8 & -1.7 & 4805.2 & 2.0 & 627.2 & -5.0 & 4445.5 & 1.9 \\
\hline
\end{tabular}

From the computational point of view, the occurrence of contact between the steel ball and massive solid is determined by evaluating the relative indentation at any instant of time during the numerical solution of the dynamic equations of motion. In the present study, the contact detection between bodies is performed by using a time steeping approach [50]. The time histories of the contact forces for the different models are plotted in Figs. 6 up to 9. These plots are for the impact velocity of $0.094 \mathrm{~m} / \mathrm{s}$ and $0.5 \mathrm{~m} / \mathrm{s}$, and for the two cylindrical specimens, respectively. In addition, Table 4 presents the maximum contact force and the percentage error for all contact force models, for the two different specimens $\mathrm{C} 1$ and $\mathrm{C} 2$, and for two different impact velocities. It can be observed that for low impact velocities and elastic materials, the outcomes do not differ in a significant manner from the Hertz contact law. In this case, the percentage error in the maximum contact force reaches $2.0 \%$, as it can be observed from Table 4. In contrast, for a soft material and higher impact velocities, the dissipative force models exhibit significant deviations from the experimental data, as it is shown in the plots of Fig. 7. Moreover, the maximum contact force exhibits large differences (6.2\% for the Lee and Wang force model), when compared with the experimental data. This 
fact can be explained by the resulting permanent indentation verified experimentally, and not considered in the present force models [100]. In fact, the contact force models utilized are valid solely for impact velocities much lower than the propagation speed of elastic waves across the bodies, i.e., $\dot{\delta}^{(-)} \ll 10^{-5} \sqrt{E} / \rho$. The quantity $\sqrt{E / \rho}$, the wave propagation speed, is the larger of two propagation speeds of the elastic deformation waves in the colliding bodies, where $E$ is the Young modulus and $\rho$ is the material mass density [147]. Impact at higher velocities, significantly exceeding the propagation velocity of the elastic deformation waves, is likely to dissipate energy in the form of permanent indentation [42, 48, 52].

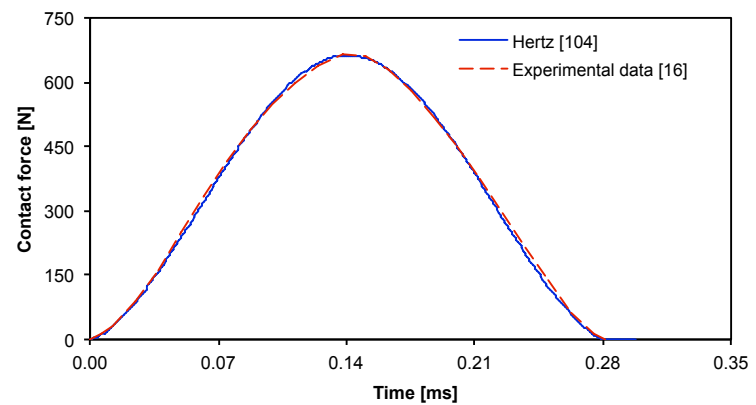

(a)

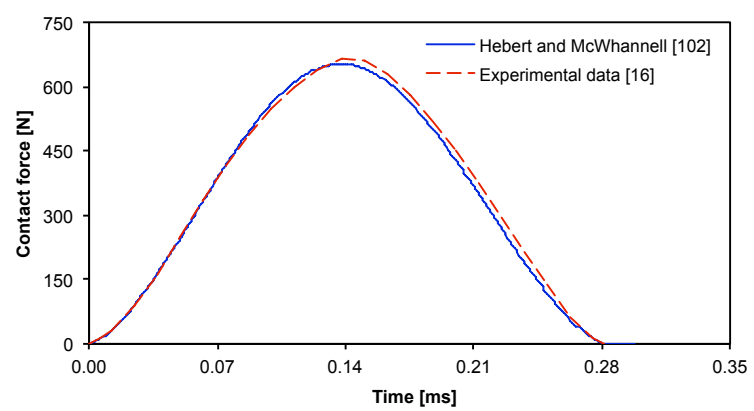

(c)

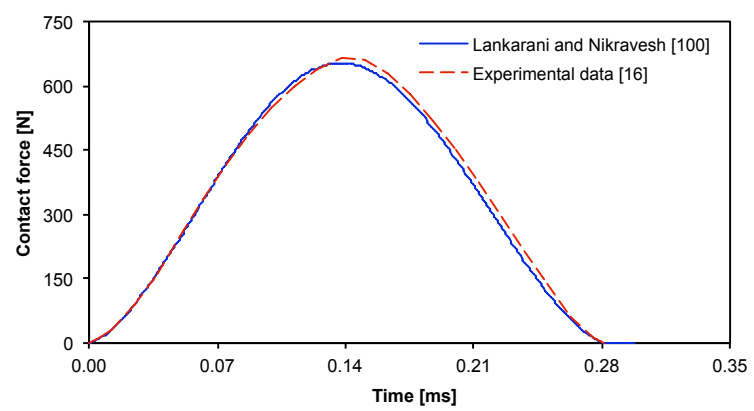

(e)

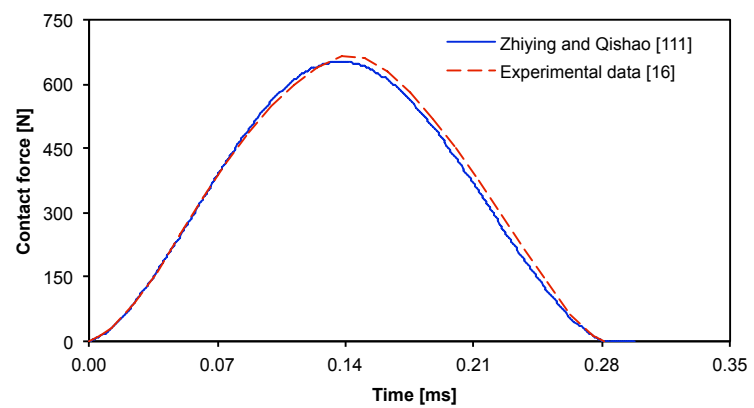

(g)

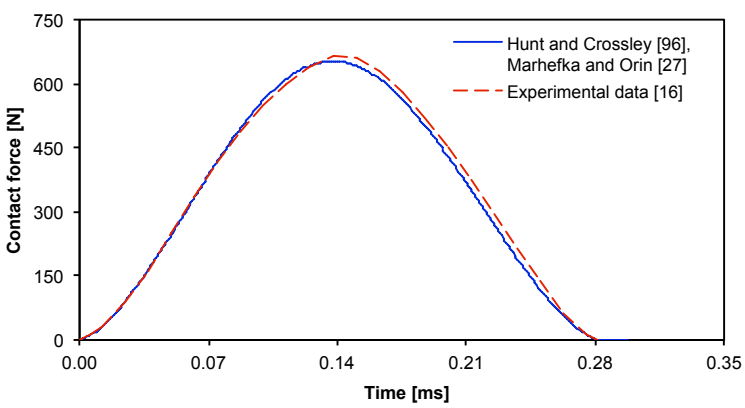

(b)

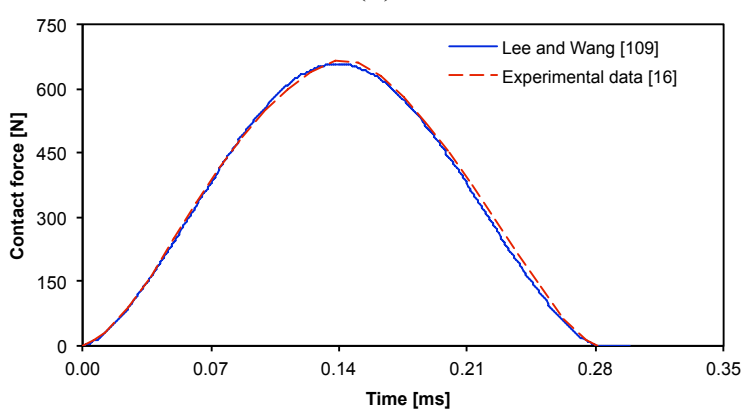

(d)

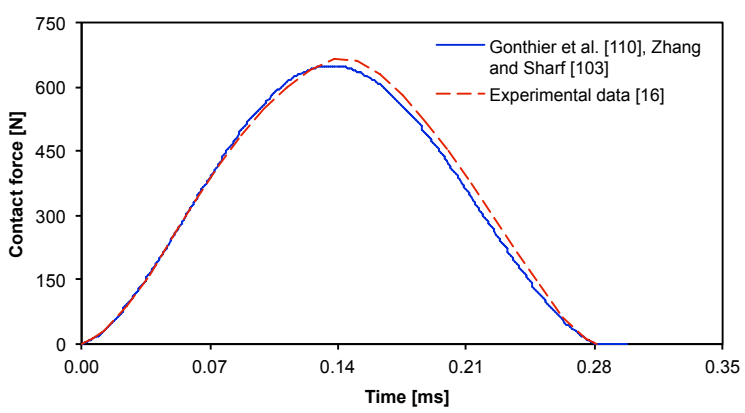

(f)

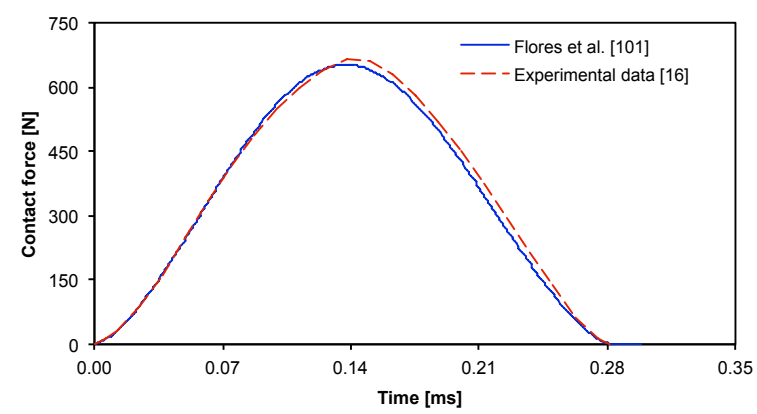

(h)

Fig. 6 Comparison of the contact force time histories for specimen C1, impact velocity of $0.094 \mathrm{~m} / \mathrm{s}$ and eight different contact force models: (a) Hertz; (b) Hunt and Crossley, Marefka and Orin; (c) Herbert and McWhannell; (d) Lee and Wang; (e) Lankarani and Nikravesh; (f) Gonthier et al., Zhang and Sharf; (g) Zhiying and Qishao; (h) Flores et al. 


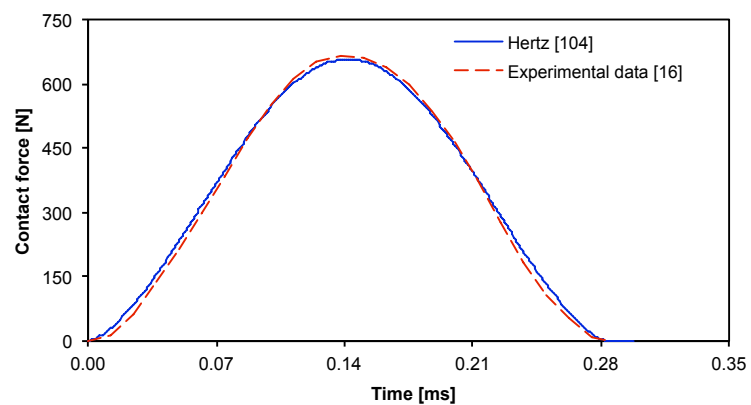

(a)

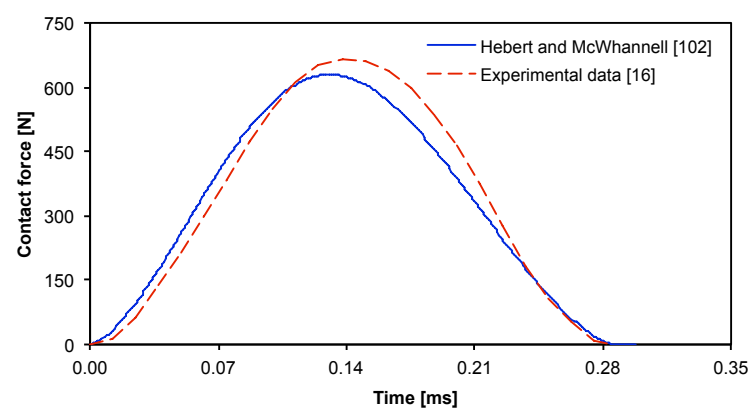

(c)

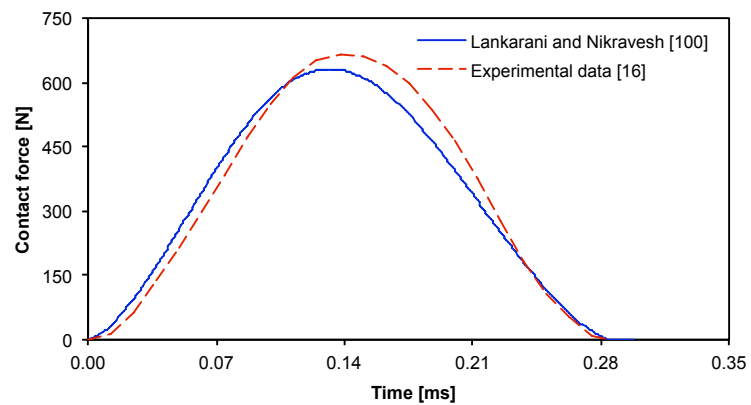

(e)

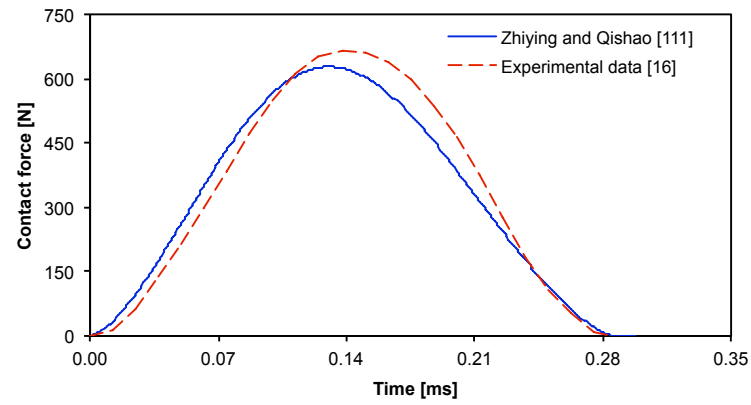

(g)

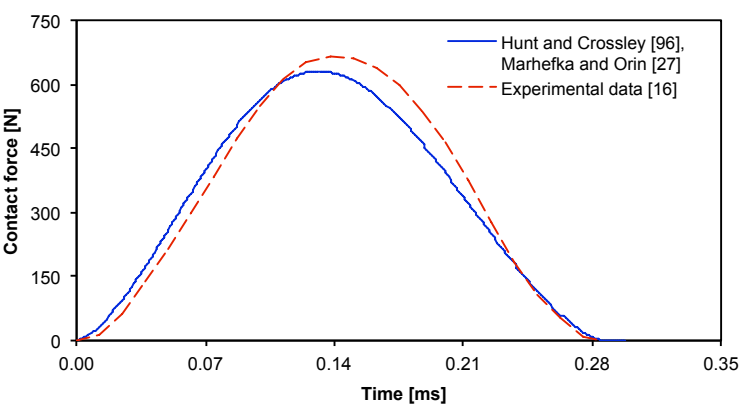

(b)

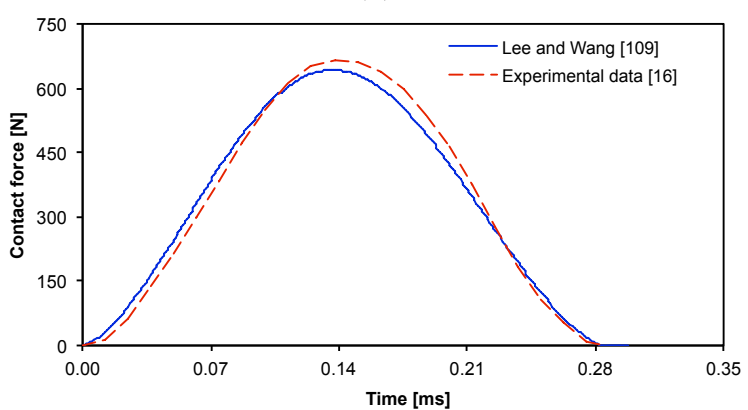

(d)

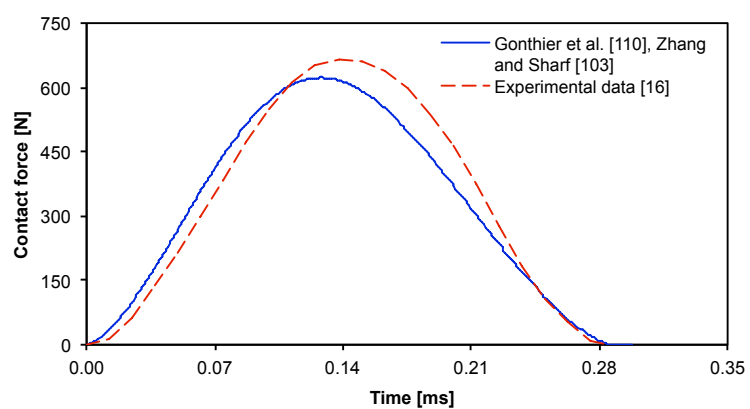

(f)

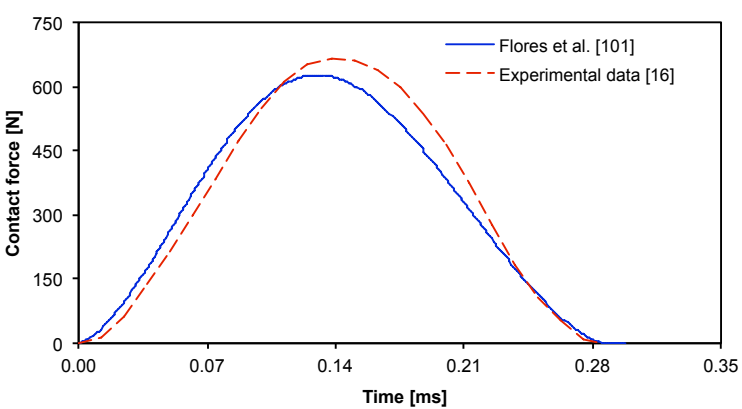

(h)

Fig. 7 Comparison of the contact force time histories for specimen C2, impact velocity of $0.094 \mathrm{~m} / \mathrm{s}$ and eight different contact force models: (a) Hertz; (b) Hunt and Crossley, Marefka and Orin; (c) Herbert and McWhannell; (d) Lee and Wang; (e) Lankarani and Nikravesh; (f) Gonthier et al., Zhang and Sharf; (g) Zhiying and Qishao; (h) Flores et al. 


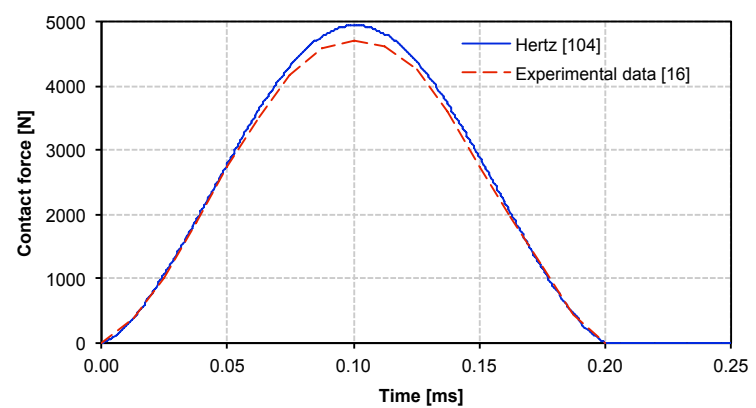

(a)

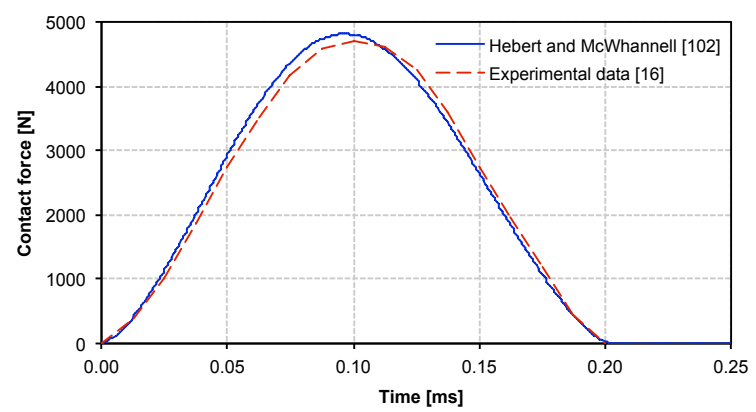

(c)

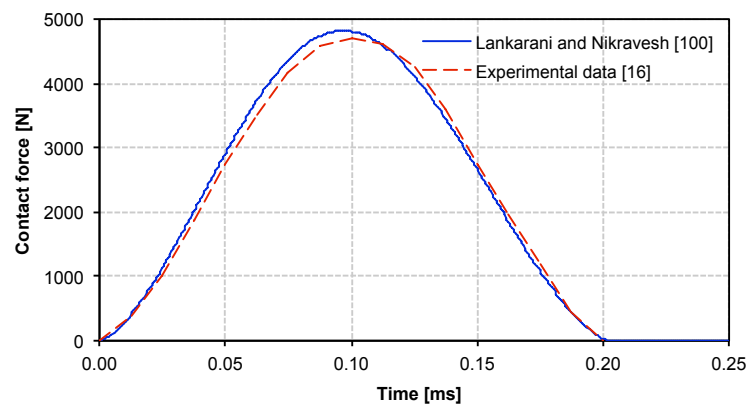

(e)

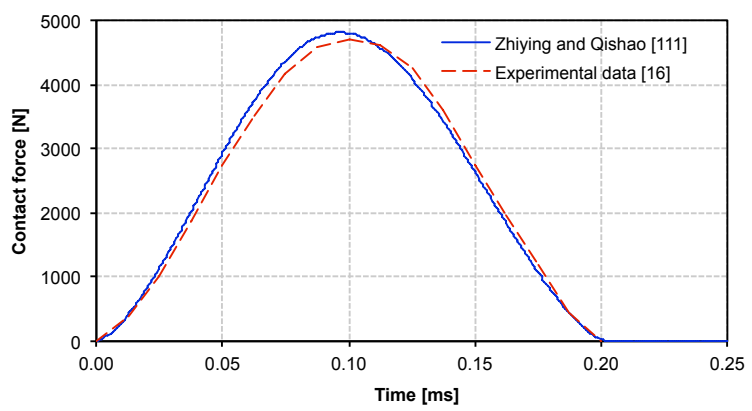

(g)

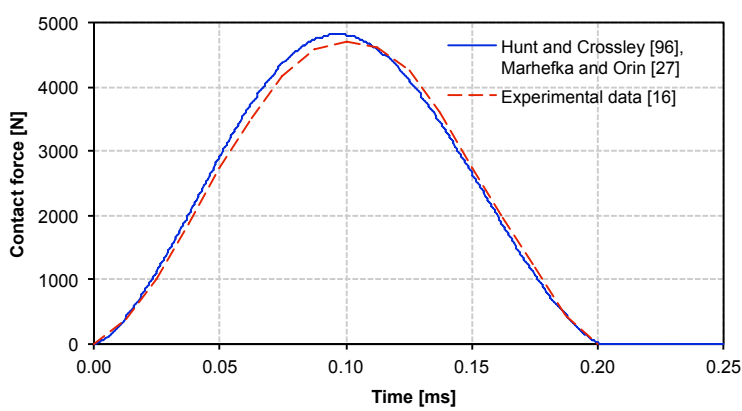

(b)

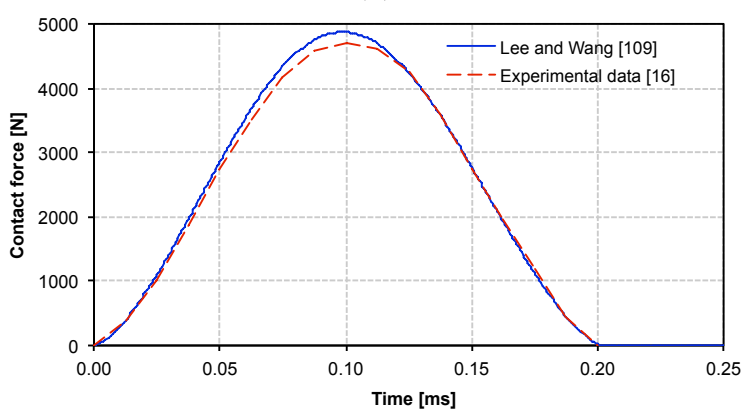

(d)

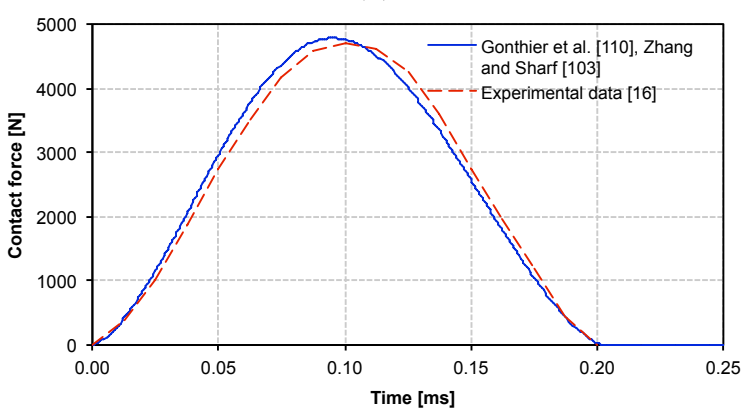

(f)

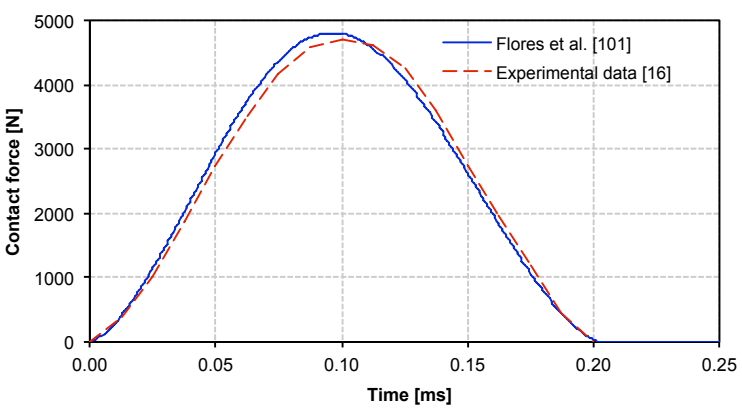

(h)

Fig. 8 Comparison of the contact force time histories for specimen $\mathrm{C} 1$, impact velocity of $0.5 \mathrm{~m} / \mathrm{s}$ and eight different contact force models: (a) Hertz; (b) Hunt and Crossley, Marefka and Orin; (c) Herbert and McWhannell; (d) Lee and Wang; (e) Lankarani and Nikravesh; (f) Gonthier et al., Zhang and Sharf; (g) Zhiying and Qishao; (h) Flores et al. 


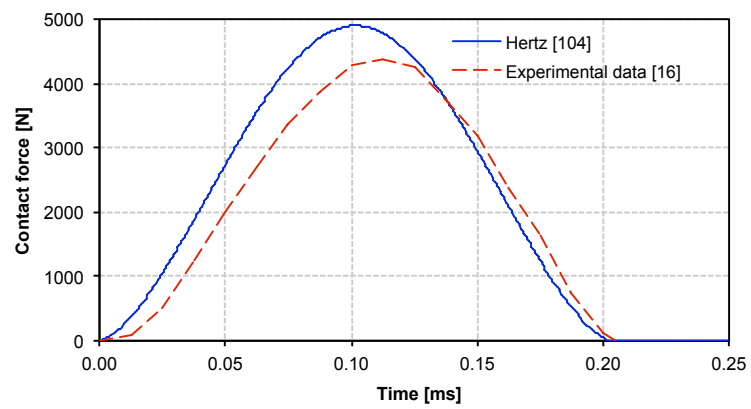

(a)

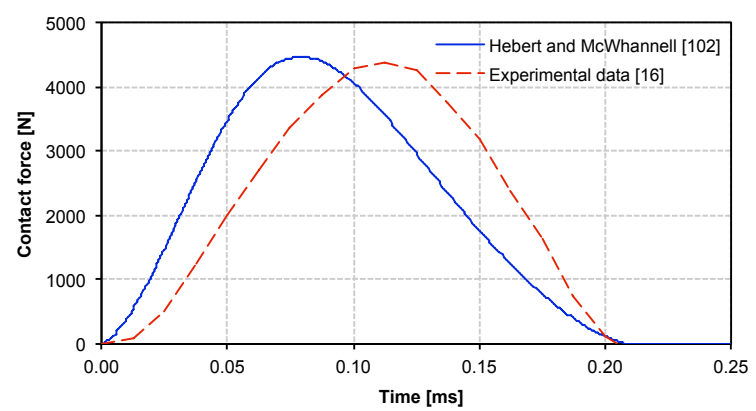

(c)

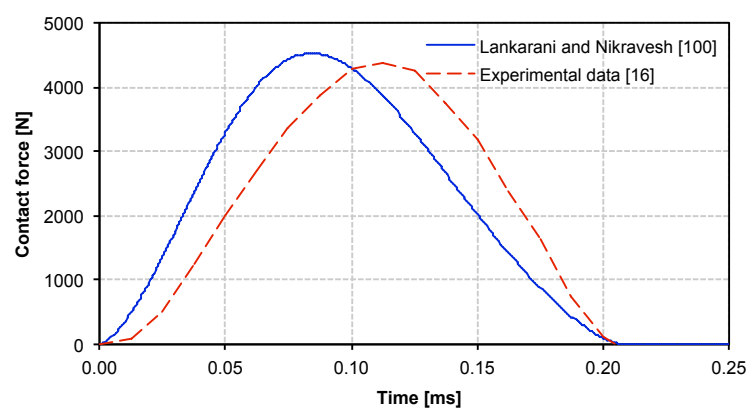

(e)

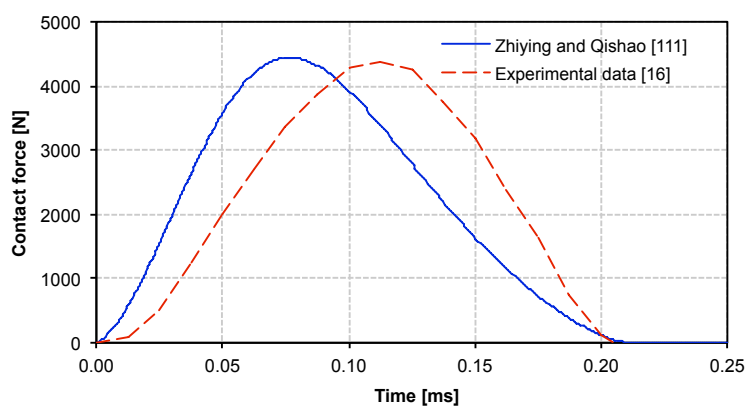

(g)

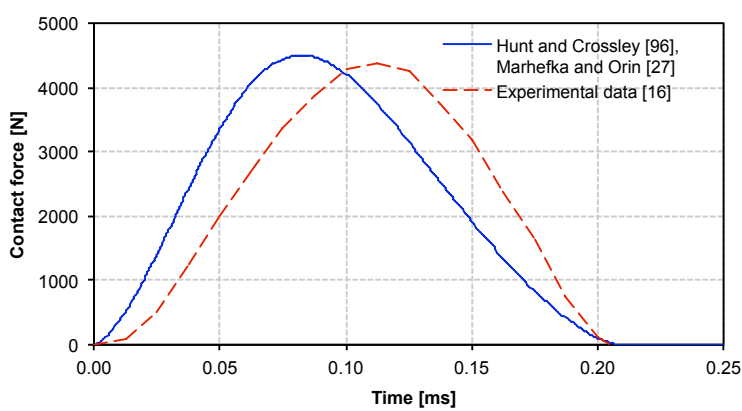

(b)

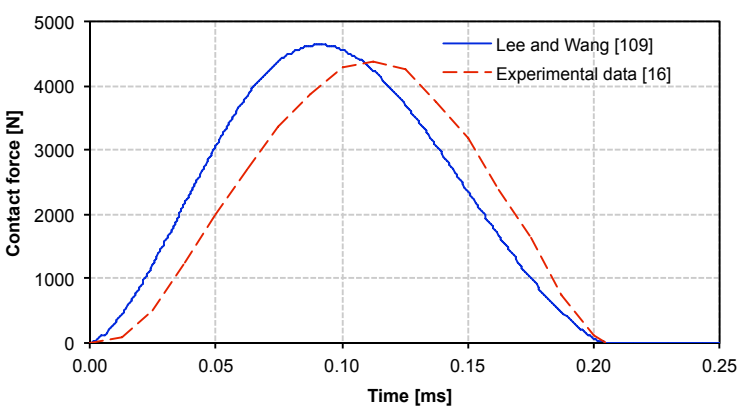

(d)

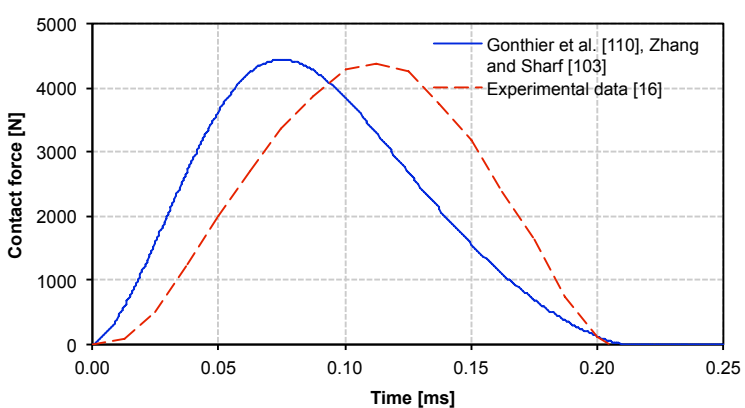

(f)

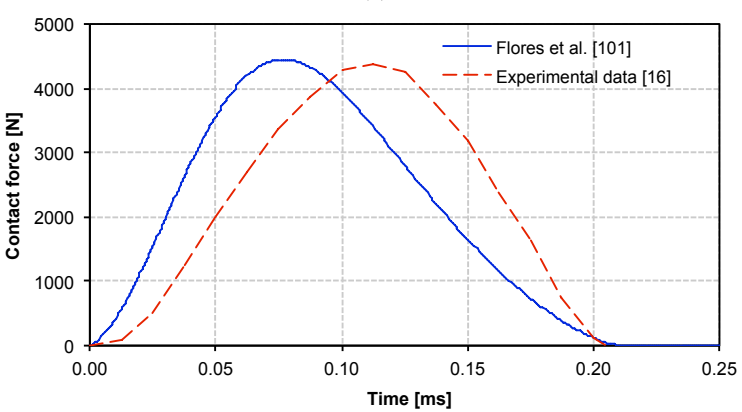

(h)

Fig. 9 Comparison of the contact force time histories for specimen C2, impact velocity of $0.5 \mathrm{~m} / \mathrm{s}$ and eight different contact force models: (a) Hertz; (b) Hunt and Crossley, Marefka and Orin; (c) Herbert and McWhannell; (d) Lee and Wang; (e) Lankarani and Nikravesh; (f) Gonthier et al., Zhang and Sharf; (g) Zhiying and Qishao; (h) Flores et al. 


\section{Concluding remarks}

The goal of the present work was to present a thorough examination of the main features of several different penalty-force based approaches frequently utilized in the context of multibody system dynamics to model and analyze contact-impact events. Special emphasis was given to the dynamic response of dissipative approaches, all based on internal damping. The similarities and differences were observed by considering simple application examples, namely the impact between two spheres and the impact of a steel ball with different cylindrical specimens. The outputs were compared with the analytical solution for a classical contact problem of a ball impacting on a massive solid. The results showed that for "low" to "medium" values of the coefficient of restitution, some of the approaches such as Gonthier et al., Flores et al., and Zhiying and Qishao do a better job on predicting the nature of energydissipation in impact. For larger coefficients of restitution, closer to unity, almost all dissipative contact force models predict similar responses. Furthermore, computational results were compared with experimental ones for a simple test case. It was observed that the force magnitude errors are all small for the computational models compared with the experimental data, which indicates that all the models behave well in the prediction of the contact forces, except at higher impact velocities for the original Hertzian contact model. Consequently, the contact models with hysteresis damping factor perform reasonably well for small impact velocities much lower than the propagation of the elastic waves in the two solids in contact (in the case of steel ball relative impact speed of $0.09 \mathrm{~m} / \mathrm{s}$ ). The recommendation from this study is that the modeling and simulation of multibody impact problems can be performed considering any of the dissipative contact force models presented when the value of the coefficient of restitution is greater than 0.7 . For more plastic impact ("low" to "medium" values of the coefficient of restitution), specific models should be utilized, namely those that account for more energy dissipation during the impact process. Also, at impact speeds comparable to the speed of propagation of the stress waves of the two solids in contact, the dissipative approach adopted in this work needs to be replaced by other that models energy dissipation in terms of the local plasticity of the contact zones.

\section{Acknowledgments}

The first and fourth authors express, respectively, their gratitude to the Portuguese Foundation for the Science and Technology for the PhD grant (SFRH/BD/78251/2011), and for the postdoctoral scholarship (SFRH/BPD/77831/2011).

\section{References}

[1] Rahnejat, H.: Multi-body dynamics: Historical evolution and application. Proceedings of the Institution of Mechanical Engineers, Part C: Journal of Mechanical Engineering Science, 214, 149-173 (2000)

[2] Eberhard, P., Schiehlen, W.: Computational dynamics of multibody systems: History, formalisms, and applications. Journal of Computational and Nonlinear Dynamics, 1, 3-12 (2006)

[3] Schiehlen, W.: Research trends in multibody system dynamics. Multibody System Dynamics, 18, 3-13 (2007)

[4] Nikravesh, P.E.: Newtonian-based methodologies in multi-body dynamics. Proceedings of the Institution of Mechanical Engineers, Part K: Journal of Multi-body Dynamics, 222, 277-288 (2008)

[5] Nikravesh, P.E.: Computer-aided analysis of mechanical systems. Prentice Hall, Englewood Cliffs, New Jersey (1988)

[6] Flores, P., Ambrósio, J., Claro, J.C.P., Lankarani, H.M.: Kinematics and dynamics of multibody systems with imperfect joints: Models and case studies. In Lecture Notes in Applied and Computational Mechanics Vol. 34, Berlin Heidelberg, New York, Springer Verlag (2008)

[7] Nikravesh, P.E.: Planar multibody dynamics: Formulation, programming and applications. CRC Press, London (2008) 
[8] Flores, P.: Modeling and simulation of wear in revolute clearance joints in multibody systems. Mechanism and Machine Theory, 44, 1211-1222 (2009)

[9] Ambrósio, J., Veríssimo, P.: Improved bushing models for general multibody systems and vehicle dynamics. Multibody System Dynamics, 22, 341-365 (2009)

[10] Machado, M., Flores, P., Claro, J.C.P., Ambrósio, J., Silva, M., Completo, A., Lankarani, H.M.: Development of a planar multi-body model of the human knee joint. Nonlinear Dynamics, 60, 459-478 (2010)

[11] Dopico, D., Luaces, A., Gonzalez, M., Cuadrado, J.: Dealing with multiple contacts in a human-in-the-loop application. Multibody System Dynamics, 25, 167-183 (2010)

[12] Koshy, C.S., Flores, P., Lankarani, H.M.: Study of the effect of contact force model on the dynamic response of mechanical systems with dry clearance joints: computational and experimental approaches. Nonlinear Dynamics, 73(1-2), 325-338 (2013)

[13] Tian, Q., Liu, C., Machado, M., Flores, P.: A new model for dry and lubricated cylindrical joints with clearance in spatial flexible multibody systems. Nonlinear Dynamics, 64, 25-47 (2011)

[14] Ebrahimi, S., Hippmann, G., Eberhard, P.: Extension of polygonal contact model for flexible multibody systems. International Journal of Applied Mathematics and Mechanics, 1, 33-50 (2005)

[15] Hirschkorn, M., McPhee, J., Birkett, S.: Dynamic modeling and experimental testing of a piano action mechanism. Journal of Computational and Nonlinear Dynamics, 1, 47-55 (2006)

[16] Zhang, Y., Sharf, I.: Validation of nonlinear viscoelastic contact force models for low speed impact. Journal of Applied Mechanics, 76, 051002, 12p. (2009)

[17] Choi, J., Ryu, H.S., Kim, C.W., Choi, J.H.: An efficient and robust contact algorithm for a compliant contact force model between bodies of complex geometry. Multibody System Dynamics, 23, 99-120 (2010)

[18] Bhalerao, K.D., Anderson, K.S.: Modeling intermittent contact for flexible multibody systems. Nonlinear Dynamics, 60, 63-79 (2010)

[19] Minamoto, H., Kawamura, S.: Moderately high speed impact of two identical spheres. International Journal of Impact Engineering, 38, 123-129 (2011)

[20] Flores, P., Leine, R., Glocker, C.: Application of the nonsmooth dynamics approach to model and analysis of the contact-impact events in cam-follower systems. Nonlinear Dynamics, 69, 2117-2133 (2012)

[21] Shabana, A.A., Zaazaa, K.E., Escalona, J.L., Sany, J.R.: Development of elastic force model for wheel/rail contact problems. Journal of Sound and Vibration, 269, 295-325 (2004)

[22] Pombo, J., Ambrósio, J., Pereira, M., Lewis, R., Dwyer-Joyce, R., Ariaudo, C., Kuka, N.: A study on wear evaluation of railway wheels based on multibody dynamics and wear computation. Multibody System Dynamics, 24, 347-366 (2010)

[23] Pombo, J., Ambrósio, J.: Multiple pantograph interaction with catenaries in high-speed trains. Journal of Computational and Nonlinear Dynamics, 7, 041008, 7p. (2012)

[24] Beheshti, H.K., Lankarani, H.M.: A simplified test methodology for crashworthiness evaluation of aircraft seat cushions. International Journal of Crashworthiness, 11, 27-35 (2006)

[25] Sousa, L., Veríssimo, P., Ambrósio, J.: Development of generic multibody road vehicle models for crashworthiness. Multibody System Dynamics, 19, 133-158 (2008).

[26] Carvalho, M., Ambrósio, J.: Development of generic road vehicle multibody models for crash analysis using an optimization approach. International Journal of Crashworthiness, 16, 537-556 (2011)

[27] Marhefka, D.W., Orin, D.E.: A compliant contact model with nonlinear damping for simulation of robotic systems. IEEE Transactions on Systems, Man and Cybernetics - Part A: Systems and Humans, 29, 566-572 (1999)

[28] Verscheure, D., Sharf, I., Bruynincky, H., Swevers, J., De Schutter, J.: Identification of contact dynamics parameters from stiff multi-point contact robotic operations. International Journal of Robotics Research, 29, 367-385 (2010)

[29] Bi, S-S., Zhou, X-D., Marghitu, D.B.: Impact modelling and analysis of the compliant legged robots. Proceedings of the Institution of Mechanical Engineers, Part K: Journal of Multi-body Dynamics, 226, 85-94 (2012)

[30] Askari, E., Flores, P., Dabirrahmani, D., Appleyard, R.: Study of the friction-induced vibration and contact mechanics of artificial hip joints. Tribology International, 70, 1-10 (2014)

[31] Silva, P., Silva, M.T., Martins, J.: Evaluation of the contact forces developed in the lower limb/orthosis interface for comfort design. Multibody System Dynamics, 24, 367-388 (2010)

[32] Argatov, I.: Development of an asymptotic modeling methodology for tibio-femoral contact in multibody dynamic simulations of the human knee joint. Multibody System Dynamics, 28, 3-20 (2012)

[33] Erkaya, S., Uzmay, I.: A neural-genetic (NN-GA) approach for optimizing mechanisms having joints with clearance. Multibody System Dynamics, 20, 69-83 (2008)

[34] Flores, P., Lankarani, H.M.: Spatial rigid-multibody systems with lubricated spherical clearance joints: modeling and simulation. Nonlinear Dynamics, 60, 99-114 (2010)

[35] Xu, L-X., Yang, Y-H., Li, Y-G., Li, C-H., Wang, S-Y.: Modeling and analysis of planar multibody systems containing deep groove ball bearing with clearance. Mechanism and Machine Theory, 56, 69-88 (2012)

[36] Izadbakhsh, A., McPhee, J., Birkett, S.: Dynamic modeling and experimental testing of a piano action mechanism with a flexible hammer shank. Journal of Computational and Nonlinear Dynamics, 3, 031004, 10p. (2008) 
[37] Lankarani, H.M.: A Poisson-Based Formulation for Frictional Impact Analysis of Multibody Mechanical Systems With Open or Closed Kinematic Chains. Journal of Mechanical Design, 122(4), 489-497 (1999)

[38] Lankarani, H.M, Nikravesh, P.E.: Application of the Canonical Equations of Motion in Problems of Constrained Multibody Systems with Intermittent Motion. Advances in Design Automation, Vol. 14, 417-423 (1998)

[39] Machado, M., Moreira, P., Flores, P., Lankarani, H.M.: Compliant contact force models in multibody dynamics: Evolution of the Hertz contact theory. Mechanism and Machine Theory, 53, 99-121 (2012)

[40] Khulief, Y.A.: Modeling of impact in multibody systems: An overview. Journal of Computational and Nonlinear Dynamics, 8, 021012, 15p. (2013)

[41] Flores, P., Leine, R., Glocker, C.: Modeling and analysis of planar rigid multibody systems with translational clearance joints based on the non-smooth dynamics approach. Multibody System Dynamics, 23, 165-190 (2010)

[42] Lankarani, H.M.: Canonical equations of motion and estimation of parameters in the analysis of impact problems. PhD Dissertation, The University of Arizona, Tucson, Arizona, USA (1988)

[43] Roy, A., Carretero, J.A.: A damping term based on material properties for the volume-based contact dynamics model. International Journal of Non-linear Mechanics, 47, 103-112 (2012)

[44] Johnson, K.L.: Contact mechanics. Cambridge University Press (1985)

[45] Greenwood, D.T.: Principles of dynamics. Prentice Hall, Englewood Cliffs, New Jersey (1965)

[46] Flores, P., Ambrósio, J., Claro, J.C.P., Lankarani, H.M.: Dynamic behaviour of planar multibody systems including revolute joints with clearance. Proceedings of the Institution of Mechanical Engineers, Part K: Journal of Multi-body Dynamics, 221, 161-174 (2007)

[47] Pereira, M.S., Nikravesh, P.E.: Impact dynamics of multibody systems with frictional contact using joint coordinates and canonical equations of motion. Nonlinear Dynamics, 9, 53-71 (1994)

[48] Shivaswamy, S., Lankarani, H.M.: Impact analysis of plate using quasi-static approach. Journal of Mechanical Design, 119, 376-381 (1997)

[49] Machado, M., Flores, P., Ambrósio, J., Completo, A.: Influence of the contact model on the dynamic response of the human knee joint. Proceedings of the Institution of Mechanical Engineers, Part K: Journal of Multi-body Dynamics, 225, 344-358 (2011)

[50] Flores, P., Ambrósio, J.: On the contact detection for contact-impact analysis in multibody systems. Multibody System Dynamics, 24, 103-122 (2010)

[51] Khulief, Y.A., Shabana, A.A.: A continuous force model for the impact analysis of flexible multibody systems. Mechanism and Machine Theory, 22, 213-224 (1987)

[52] Lankarani, H.M., Nikravesh, P.E.: Continuous contact force models for impact analysis in multibody systems. Nonlinear Dynamics, 5, 193-207 (1994)

[53] Dias, J.M.P., Pereira, M.S.: Dynamics of flexible mechanical systems with contact-impact and plastic deformations. Nonlinear Dynamics, 8, 491-512 (1995)

[54] Pfeiffer, F., Glocker, C.: Multibody dynamics with unilateral constraints. John Wiley and Sons, New York (1996)

[55] Förg, M., Pfeiffer, F., Ulbrich, H.: Simulation of unilateral constrained systems with many bodies. Multibody System Dynamics, 14, 137-154 (2005)

[56] Ebrahimi, S. Eberhard, P.: A linear complementarity formulation on position level for frictionless impact of planar deformable bodies. ZAMM Z. Angew. Math. Mech., 86, 807-817 (2006)

[57] Acary, V., Brogliato, B.: Numerical methods for nonsmooth dynamical systems: Applications in mechanics and electronics. In Lecture Notes in Applied and Computational Mechanics, Vol. 35, Berlin Heidelberg, New York, Springer-Verlag (2008)

[58] Brogliato, B., Ten Dam, A.A., Paoli, L., Genot, F., Abadie, M.: Numerical simulations of finite dimensional multibody nonsmooth mechanical systems. Applied Mechanics, 55, 107-150 (2002)

[59] Glocker, C., Pfeiffer, F.: Complementarity problems in multibody systems with planar friction. Archive of Applied Mechanics, 63, 452-463 (2003)

[60] Pang, J., Trinkle, J.C.: Complementarity formulations and existence of solutions of dynamic multi-rigid-body contact problems with Coulomb friction. Mathematical Programming, 73, 199-226 (1996)

[61] Pfeiffer, F.: The idea of complementarity in multibody dynamics. Archive of Applied Mechanics, 72, 807-816 (2003)

[62] Signorini, A.: Sopra alcune questioni di elastostatica. Atti della Societa Italian per il Progresso della Scienza (1933)

[63] Moreau, J.J.: Application of convex analysis to some problems of dry friction. Trends in Applications of Pure Mathematics to Mechanics, (H. Zorski, Ed.) London, UK, Pitman, 2, 263-349 (1979)

[64] Panagiotopoulos, P.D.: Inequality problems in mechanics and applications. Convex and Nonconvex Energy Functionals. Birkhäuser-Verlag, Basel, Boston, Stuttgart (1985)

[65] Kwak, B.M.: Complementarity problem formulation of three-dimensional frictional contact. Journal of Applied Mechanics, 58, 134-140 (1991)

[66] Anitescu, M., Potra, F.A.: Formulating dynamic multi-rigid-body contact problems with friction as solvable linear complementarity problems. Nonlinear Dynamics, 14, 231-247 (1997)

[67] Brogliato, B.: Some perspectives on the analysis and control of complementarity systems. IEEE Transactions on Automatic Control, 48, 918-935 (2003) 
[68] Goldsmith, W.: Impact - The theory and physical behaviour of colliding solids. Edward Arnold Ltd, London, England (1960)

[69] Stronge, W.J.: Impact mechanics. Cambridge Press, Cambridge (2000)

[70] Wriggers, P.: Computational contact mechanics. Second edition, Springer-Verlag, Berlin (2006)

[71] Kozlov, V.V., Treshchev, D.V.: A generic introduction to the dynamics of system with impacts. American Mathematical Society (1991)

[72] Newton, I.: Mathematical Principles of Natural Philosophy, London (1687)

[73] Gilardi, G., Sharf, I.: Literature survey of contact dynamics modeling. Mechanism and Machine Theory, 37, 12131239 (2002)

[74] Atanackovic, T.M., Spasic, D.T.: On viscoelastic compliant contact-impact models. Journal of Applied Mechanics, 71, 134-138 (2004)

[75] Font-Llagunes, J., Barjau, A., Pàmies-Vilà, R., Kövecses, J.: Dynamic analysis of impact in swing-through crutch gait using impulsive and continuous contact models. Multibody System Dynamics, 28, 257-282 (2012)

[76] Flores, P., Ambrósio, J., Claro, J.C.P., Lankarani, H.M.: Translational joints with clearance in rigid multi-body systems. Journal of Computational and Nonlinear Dynamics, 3, 0110071, 10p. (2008)

[77] Brach, R.M.: Mechanical impact dynamics, rigid body collisions. John Wiley \& Sons, New York (1991)

[78] Beer, F.B., Johnston, E.R.: Vector mechanics for Engineers. Statics and Dynamics, McGraw-Hill (1997)

[79] Moradi, E., Beheshti, H.K., Lankarani, H.M.: Lumbar load attenuation for rotorcraft occupants using a design methodology for the seat impact energy-absorbing system. Central European Journal of Engineering, 2, 562-577 (2012)

[80] Lazan, B.: Damping of materials and members in structural mechanics. Pergamon Press (1968)

[81] Nashif, A.D.: Vibration damping. Wiley-Interscience Publication (1985)

[82] Yigit, A.S., Christoforou, A.P., Majeed, M.A.: A nonlinear visco-elastoplastic impact model and the coefficient of restitution. Nonlinear Dynamics, 66, 509-521 (2011)

83] Thornton, C.: Coefficient of restitution for collinear collisions of elastic-perfectly plastic spheres. Journal of Applied Mechanics, 64, 383-386 (1997)

[84] Vu-Quoc, L., Zhang, X., Lesburg, L.: A normal force-displacement model for contacting spheres accounting for plastic deformation: force-driven formulation. Journal of Applied Mechanics, 67, 363-371 (2000)

[85] Wu, C-Y., Li, L-Y., Thornton, C.: Energy dissipation during normal impact of elastic and elastic-plastic spheres. International Journal of Impact Engineering, 32, 593-604 (2005)

[86] Dietl, P., Wensing, J., van Nijen, G.C.: Rolling bearing damping for dynamic analysis of multi-body systems experimental and theoretical results. Proceedings of the Institution of Mechanical Engineers, Part K: Journal of Multibody Dynamics, 214, 33-43 (2000)

[87] Sorensen, S.E., Hansen, M.R., Ebbesen, M.K., Mouritsen, O.O.: Implicit identification of contact parameters in a continuous chain model. Modeling, Identification and Control, 32, 1-15 (2011)

[88] Lopes, D.S., Silva, M.T., Ambrósio, J.A., Flores, P.: A mathematical framework for contact detection between quadric and superquadric surfaces. Multibody System Dynamics, 24(3), 255-280 (2010)

[89] Ramírez, R., Pöschel, T., Brilliantov, N.V., Schwager, T.: Coefficient of restitution of colliding viscoelastic spheres. Physical Review E, 60, 4465-4472 (1999)

[90] Luo, L., Nahon, M.: Development and validation of geometry-based compliant contact models. Journal of Computational and Nonlinear Dynamics, 6, 0110041, 11p. (2011)

[91] Seifried, R., Schiehlen, W., Eberhard, P.: The role of the coefficient of restitution on impact problems in multi-body dynamics. Proceedings of the Institution of Mechanical Engineers, Part K: Journal of Multi-body Dynamics, 224, 279-306 (2010)

[92] Najafabadi, S.A.M., Kövecses, J., Angeles, J.: Generalization of the energetic coefficient of restitution for contacts in multibody systems. Journal of Nonlinear and Computational Dynamics, 3, 0410081, 14p. (2008)

[93] Zukas, J.A., Nicholas, T., Greszczuk, L.B., Buran, D.R.: Impact dynamics. John Wiley \& Sons, New York (1982)

[94] Cross, R., The bounce of a ball. American Journal of Physics, 67, 222-227 (1999)

[95] Oden, J.T., Martins, J.A.M.: Models and computational methods for dynamic friction phenomena. Proceedings: Fenomech III in: Computer Methods in Applied Mechanics and Engineering, North Holland, Amsterdam (1984)

96] Hunt, K.H., Crossley, F.R.E.: Coefficient of restitution interpreted as damping in vibroimpact. Journal of Applied Mechanics, 7, 440-445 (1975)

[97] Bibalan, P.T., Featherstone, R.: A study of soft contact models in simulink. Proceedings of the Australasian Conference on Robotics and Automation (ACRA), December 2-4, Sydney, Australia, (2009) 8p

[98] Moreira, P., Silva, M., Flores, P.: A biomechanical multibody foot model for forward dynamic analysis. Proceedings of the 1st Joint International Conference on Multibody Dynamics, Lappeenranta, Finland, May 25-27 (2010) 10p

[99] Guess, T.M., Thiagarajan, G., Kia, M., Mishra, M.: A subject specific multibody model of the knee with menisci. Medical Engineering \& Physics, 32, 505-515 (2010)

[100] Lankarani, H.M., Nikravesh, P.E.: A contact force model with hysteresis damping for impact analysis of multibody systems. Journal of Mechanical Design, 112, 369-376 (1990) 
[101] Flores, P., Machado, M., Silva, M.T., Martins, J.M.: On the continuous contact force models for soft materials in multibody dynamics. Multibody System Dynamics, 25, 357-375 (2011)

[102] Herbert, R.G., McWhannell, D.C.: Shape and frequency composition of pulses from an impact pair. Journal of Engineering for Industry, 99, 513-518 (1977)

[103] Zhang, Y., Sharf, I.: Compliant force modeling for impact analysis. Proceedings of the 2004 ASME International Design Technical Conferences, Salt Lake City, Paper No. DETC2004-57220 (2004)

[104] Hertz, H.: Über die Berührung fester elastischer Körper, Journal reine und angewandte Mathematik 92, 156-171 (1881)

[105] Anagnostopoulos, S.A.: Pounding of buildings in series during earthquakes. Earthquake Engineering and Structural Dynamics, 16, 443-456 (1988)

[106] Ristow, G.H.: Simulating granular flow with molecular dynamics. Journal of Physics I France, 2, 649-662 (1992)

[107] Shäfer, J., Dippel, S., Wolf, E.D.: Force Schemes in Simulations of Granular Materials. Journal of Physics I France, 6, 5-20 (1996)

[108] Lee, J., Herrmann, H.J.: Angle of Repose and Angle of Marginal Stability: Molecular Dynamics of Granular Particles. Journal of Physics, A26, 373-384 (1993)

[109] Lee, T.W., Wang, A.C.: On the dynamics of intermittent-motion mechanisms, Part 1: Dynamic model and response, Journal of Mechanisms, Transmissions, and Automation in Design, 105, 534-540 (1983)

[110] Gonthier, Y., McPhee, J., Lange, C., Piedboeuf, J-C.: A regularized contact model with asymmetric damping and dwell-time dependent friction, Multibody System Dynamics, 11, 209-233 (2004)

[111] Zhiying, Q., Qishao, L.: Analysis of impact process based on restitution coefficien, Journal of Dynamics and Control, 4, 294-298 (2006)

[112] Gharib, M., Hurmuzlu, Y.: A new contact force model for low coefficient of restitution impact. Journal of Applied Mechanics, 79(6), 064506 (2012)

[113] Kuwabara, G., Kono, K.: Restitution coefficient in a collision between two spheres, Japanese Journal of Applied Physics, 26, 1230-1233 (1987)

[114] Brilliantov, N.V., Spahn, F., Hertzsch, J-M., Pöschel, T.: The collision of particles in granular systems. Physica A: Statistical Mechanics and its Applications, 231(4), 417-424 (1996)

[115] Brilliantov, N.V., Spahn, F., Hertzsch, J-M., Pöschel, T.: Model for collisions in granular gases. Physics Review E, 53, 5382-5392 (1996)

[116] Tsuji, Y., Tanaka, T., Ishida, T.: Lagrangian numerical simulation of plug flow of cohesionless particles in a horizontal pipe. Powder Technology, 71(3), 239-250 (1992)

[117] Jankowski, R.: Analytical expression between the impact damping ratio and the coefficient of restitution in the nonlinear viscoelastic model of structural pounding. Earthquake Engineering \& Structural Dynamics, 35(4), 517-524 (2006)

[118] Bordbar, M.H., Hyppänen, T.: Modeling of binary collision between multisize viscoelastic spheres. Journal of Numerical Analysis, Industrial and Applied Mathematics, 2(3-4), 115-128 (2007)

[119] Schwager, T., Pöschel, T.: Coefficient of normal restitution of viscous particles and cooling rate of granular gases. Physics Review E, 57(1), 650-654 (1998)

[120] Kruggel-Emden, H., Simsek, E., Rickelt, S., Wirtz, S., Scherer, V.: Review and extension of normal force models for the Discrete Element Method. Powder Technology, 171, 157-173 (2007)

[121] Kruggel-Emden, H., Simsek, E. Wirtz, S., Scherer, V.: Modeling of granular flow and combined heat transfer in hoppers by the Discrete Element Method (DEM). Journal of Pressure Vessel Technology, 128(3), 439-44 (2006)

[122] Limtrakul, S., Boonsrirat, A., Vatanatham, T.: DEM modeling and simulation of a catalytic gas-solid fluidized bed reactor: a spouted bed as a case study. Chemical Engineering Science, 59, 5225-5231 (2004)

[123] Lätzel, M., Luding, S., Herrmann, H.J., Howell, D.W., Behringer, R.P.: Comparing simulation and experiment of a 2D granular couette shear device. European Physical Journal. E, Soft Matter, 11, 325-333 (2003)

[124] Kuoa, H.P., Knighta, P.C., Parkerb, D.J., Tsujic, Y., Adamsd, M.J., Seville, J.P.K.: The influence of DEM simulation parameters on the particle behaviour in a V-mixer, Chemical Engineering Science, 57(17), 3621-3638 (2002)

[125] Pàmies-Vilà, R., Font-Llagunes, J.M., Lugrís, U., Cuadrado, J.: Parameter identification method for a three-dimensional foot-ground contact model. Mechanism and Machine Theory, 75, 107-116 (2014)

[126] Pereira, C.M., Ramalho, A.L., Ambrósio, J.A.: A critical overview of internal and external cylinder contact force models. Nonlinear Dynamics, 63, 681-697 (2011)

[127] Jackson, R.L., Green, I., Marghitu, D.B.: Predicting the coefficient of restitution of impacting elastic-perfectly plastic spheres. Nonlinear Dynamics, 60(3), 217-229 (2010)

[128] Machado, M., Flores, P., Dopico, D., Cuadrado, J.: Dynamic response of multibody systems with 3D contact-impact events: influence of the contact force model. Proceedings of EUROMECH Colloquium 524, Multibody System Modelling, Control and Simulation for Engineering Design, Enschede, Netherlands, February 27-29, 2p (2012)

[129] Zhang, Z., Xu, L., Flores, P., Lankarani, H.M.: A Kriging Model for the Dynamics of Mechanical Systems with Revolute Joint Clearances. ASME Journal of Computational and Nonlinear Dynamics, 9(3), 031013-13 (2014)

[130] Flores, P., Lankarani, H.M.: Dynamic response of multibody systems with multiple clearance joints. ASME Journal of Computational and Nonlinear Dynamics, 7(3), 031003-13 (2012) 
[131] Tian, Q., Sun, Y., Liu, C., Hu, H., Flores, P.: Elastohydrodynamic lubricated cylindrical joints for rigid-flexible multibody dynamics. Computers and Structures, 114-115, 106-120 (2013)

[132] Erkaya, S.: Trajectory optimization of a walking mechanism having revolute joints with clearance using ANFIS approach. Nonlinear Dynamics, 71(1-2), 75-91 (2013)

[133] Lugrís, U., Carlín, J., Pàmies-Vilà, R., Font-Llagunes, J.M., Cuadrado, J.: Solution methods for the double-support indeterminacy in human gait. Multibody System Dynamics, 30(3), 247-263 (2013)

[134] Muvengei, O., Kihiu, J., Ikua, B.: Dynamic analysis of planar rigid-body mechanical systems with two-clearance revolute joints. Nonlinear Dynamics, 73(1-2), 259-273 (2013)

[135] Carvalho, A., Suleman, A.: Multibody simulation of the musculoskeletal system of the human hand, Multibody System Dynamics, 29(3), 271-288 (2013)

[136] Piatkowski, T.: Dahl and LuGre dynamic friction models - The analysis of selected properties. Mechanism and Machine Theory, 73, 91-100 (2014)

[137] Liang, J., Fillmore, S., Ma, O.: An extended bristle friction force model with experimental validation. Mechanism and Machine Theory, 56, 123-137 (2012)

[138] Reis, V.L., Daniel, G.B., Cavalca, K.L.: Dynamic analysis of a lubricated planar slider-crank mechanism considering friction and Hertz contact effects. Mechanism and Machine Theory, 74, 257-273 (2014)

[139] Yao, W., Chen, B., Liu, C.: Energetic coefficient of restitution for planar impact in multi-rigid-body systems with friction. International Journal of Impact Engineering, 31(3), 255-265 (2005)

[140] Chang, W.R., Ling, F.F.: Normal impact model of rough surfaces. Journal of Tribology, 114, 439-447 (1992)

[141] Li, L.Y., Wu, C.Y., Thornton, C.: A theoretical model for the contact of elastoplastic bodies. Proc. Inst. Mech. Eng., C J. Mech. Eng. Sci, 216(4), 421-431 (2002)

[142] Vu-Quoc, L., Zhang, X.: An elastoplastic contact force-displacement model in the normal direction: displacement-driven version. Proc. R. Soc. Lond. A, 455(1991), 4013-4044 (1999)

[143] Anderson, R.W.G., Long, A.D., Serre, T.: Phenomenological continuous contact-impact modelling for multibody simulations of pedestrian-vehicle contact interactions based on experimental data. Nonlinear Dynamics, 58(1-2), 199208 (2009)

[144] Muller, P., Pöschel, T.: Oblique impact of frictionless spheres: on the limitations of hard sphere models for granular dynamics. Granular Matter, 14, 115-120 (2012)

[145] Liu, P.Y., Yang, R.Y., Yu, A.B.: The effect of liquids on radial segregation of granular mixtures in rotating drums. Granular Matter, 15, 427-436 (2013)

[146] Yang, J., Wu, C-Y., Adams, M.: DEM analysis of particle adhesion during powder mixing for dry powder inhaler formulation development. Granular Matter, 15, 417-426 (2013)

[147] Love, A. E. H.: A Treatise on the mathematical theory of elasticity. Fourth edition, Dover Publications, New York (1944) 


\section{Figures and Tables captions}

Fig. 1 Representation of the normal contact action between two solid spherical bodies.

Fig. 2 Resulting hysteresis damping factor as function of the coefficient of restitution for different dissipative contact force models.

Fig. 3 Force-indentation relation for different contact force models for a direct-central impact of two spheres: (a) Hunt and Crossley, Marefka and Orin; (b) Herbert and McWhannell; (c) Lee and Wang; (d) Lankarani and Nikravesh; (e) Gonthier et al., Zhang and Sharf; (f) Zhiying and Qishao; (g) Flores et al.; (h) Gharib and Hurmuzlu.

Fig. 4 Phase portraits for different contact force models for a direct-central impact of two spheres: (a) Hunt and Crossley, Marefka and Orin; (b) Herbert and McWhannell; (c) Lee and Wang; (d) Lankarani and Nikravesh; (e) Gonthier et al., Zhang and Sharf; (f) Zhiying and Qishao; (g) Flores et al.; (h) Gharib and Hurmuzlu.

Fig. 5 Impact between a steel ball and a cylindrical specimen \{Adapted from [16]\}.

Fig. 6 Comparison of the contact force time histories for specimen C1, impact velocity of $0.094 \mathrm{~m} / \mathrm{s}$ and eight different contact force models: (a) Hertz; (b) Hunt and Crossley, Marefka and Orin; (c) Herbert and McWhannell; (d) Lee and Wang; (e) Lankarani and Nikravesh; (f) Gonthier et al., Zhang and Sharf; (g) Zhiying and Qishao; (h) Flores et al.

Fig. 7 Comparison of the contact force time histories for specimen C2, impact velocity of $0.094 \mathrm{~m} / \mathrm{s}$ and eight different contact force models: (a) Hertz; (b) Hunt and Crossley, Marefka and Orin; (c) Herbert and McWhannell; (d) Lee and Wang; (e) Lankarani and Nikravesh; (f) Gonthier et al., Zhang and Sharf; (g) Zhiying and Qishao; (h) Flores et al.

Fig. 8 Comparison of the contact force time histories for specimen $\mathrm{C} 1$, impact velocity of $0.5 \mathrm{~m} / \mathrm{s}$ and eight different contact force models: (a) Hertz; (b) Hunt and Crossley, Marefka and Orin; (c) Herbert and McWhannell; (d) Lee and Wang; (e) Lankarani and Nikravesh; (f) Gonthier et al., Zhang and Sharf; (g) Zhiying and Qishao; (h) Flores et al.

Fig. 9 Comparison of the contact force time histories for specimen $\mathrm{C} 2$, impact velocity of $0.5 \mathrm{~m} / \mathrm{s}$ and eight different contact force models: (a) Hertz; (b) Hunt and Crossley, Marefka and Orin; (c) Herbert and McWhannell; (d) Lee and Wang; (e) Lankarani and Nikravesh; (f) Gonthier et al., Zhang and Sharf; (g) Zhiying and Qishao; (h) Flores et al.

Table 1 Hysteresis damping factors for different viscoelastic models, in Eq. (1).

Table 2 Properties of the contacting bodies utilized in the present work \{Adapted from [16]\}.

Table 3 Generalized contact stiffness and coefficient of restitution \{Adapted from [16]\}.

Table 4 Global results obtained in terms of maximum contact force and corresponding percentage error. 


\section{List of figures}

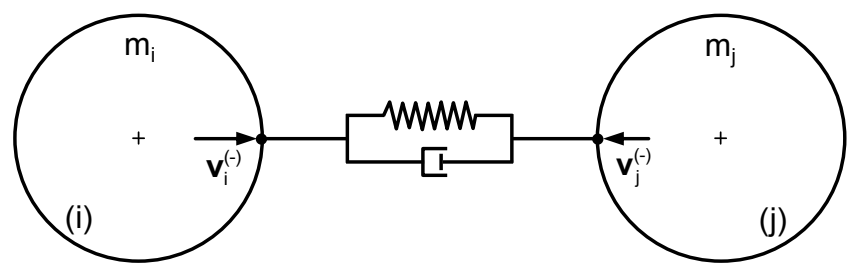

Fig. 1 Representation of the normal contact action between two solid spherical bodies.

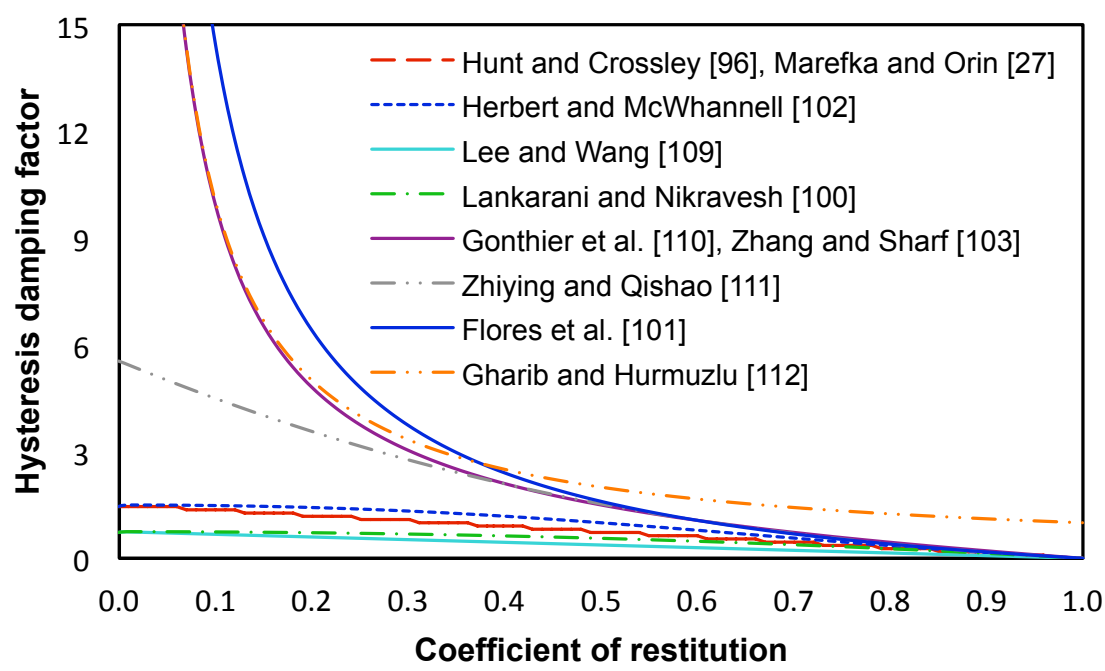

Fig. 2 Resulting hysteresis damping factor as function of the coefficient of restitution for different dissipative contact force models. 


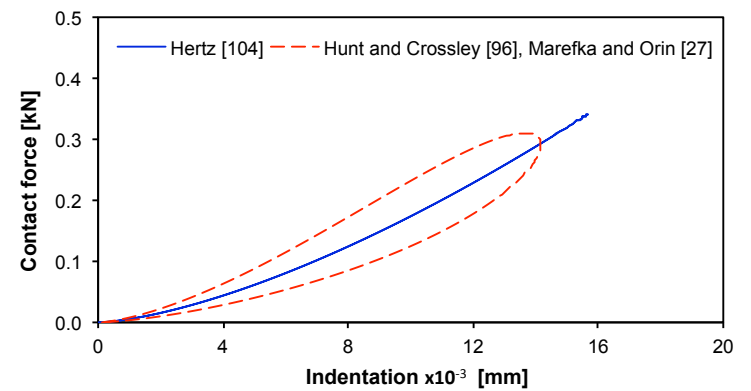

(a)

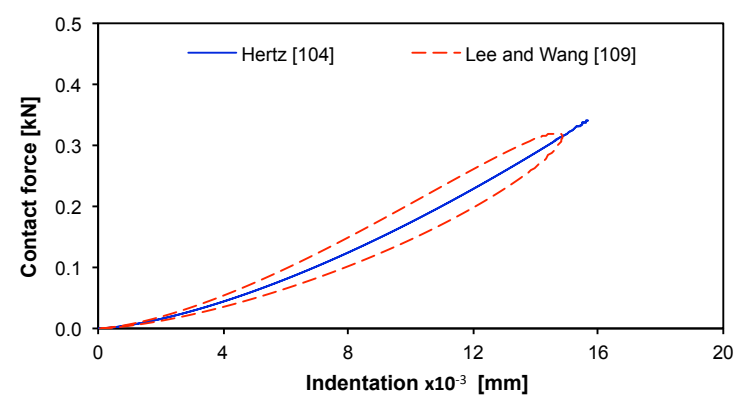

(c)

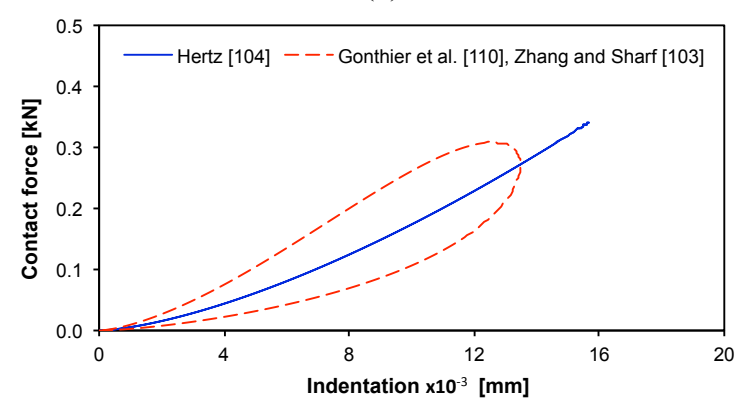

(e)

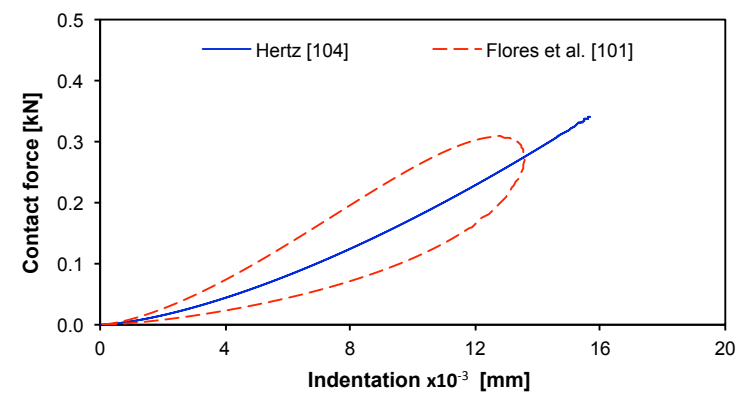

(g)

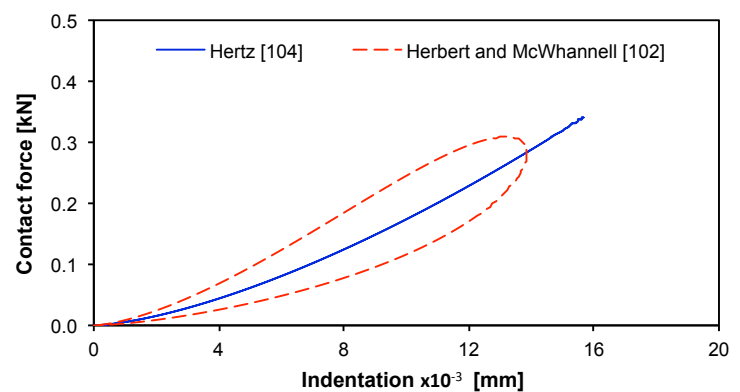

(b)

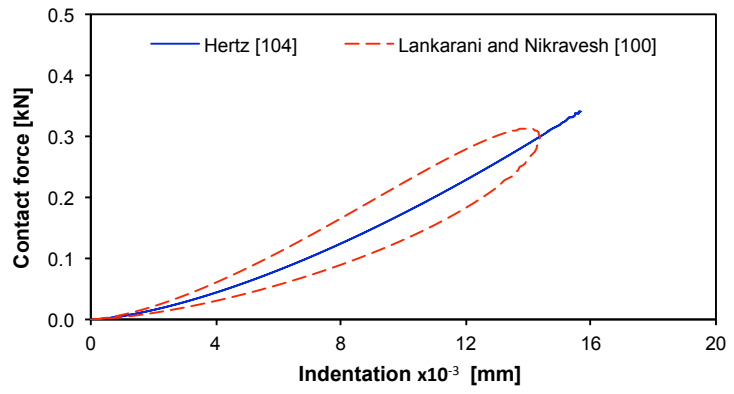

(d)

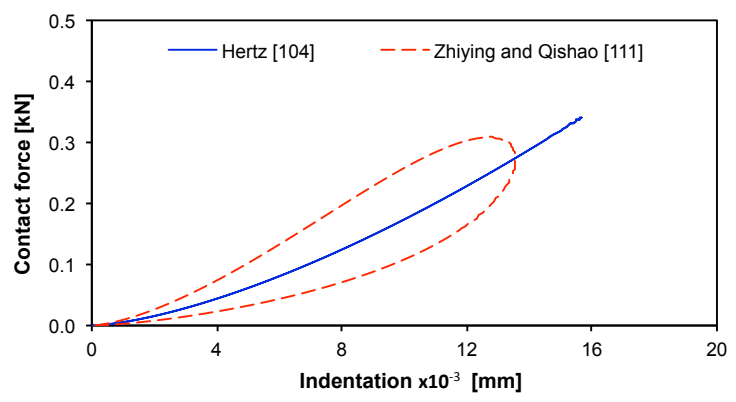

(f)

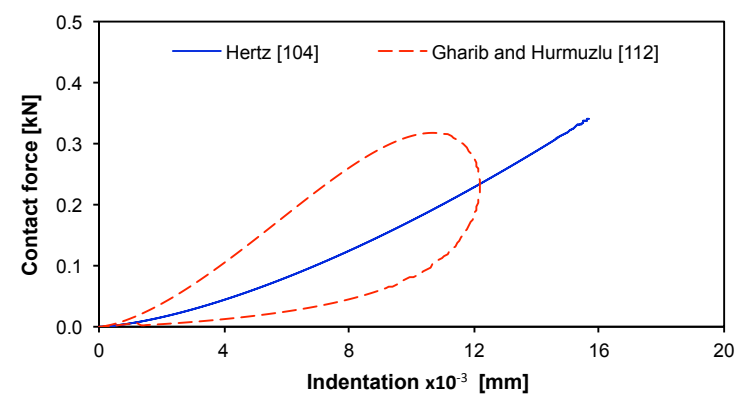

(h)

Fig. 3 Force-indentation relation for different contact force models for a direct-central impact of two spheres: (a) Hunt and Crossley, Marefka and Orin; (b) Herbert and McWhannell; (c) Lee and Wang; (d) Lankarani and Nikravesh; (e) Gonthier et al., Zhang and Sharf; (f) Zhiying and Qishao; (g) Flores et al.; (h) Gharib and Hurmuzlu. 


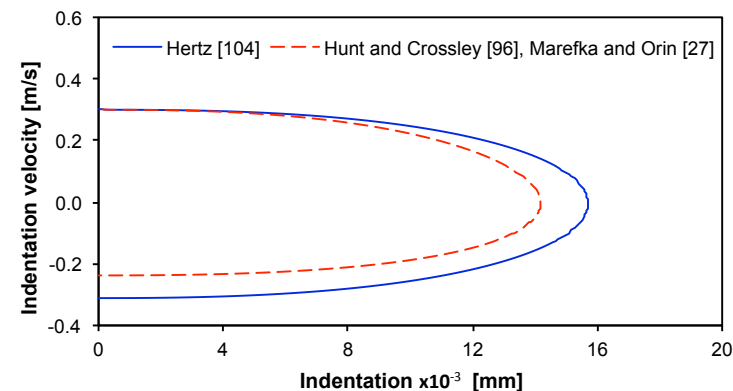

(a)

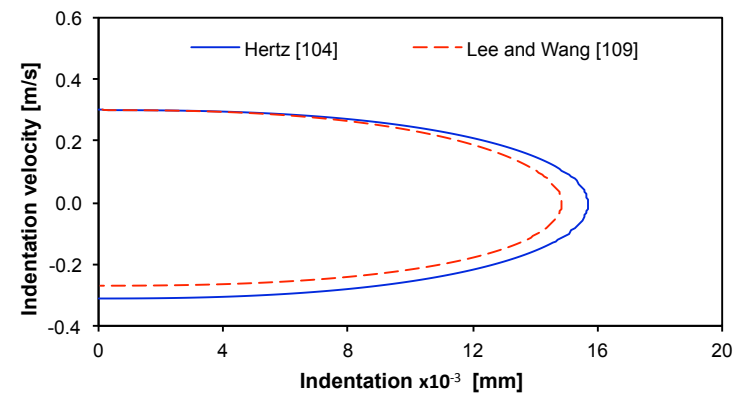

(c)

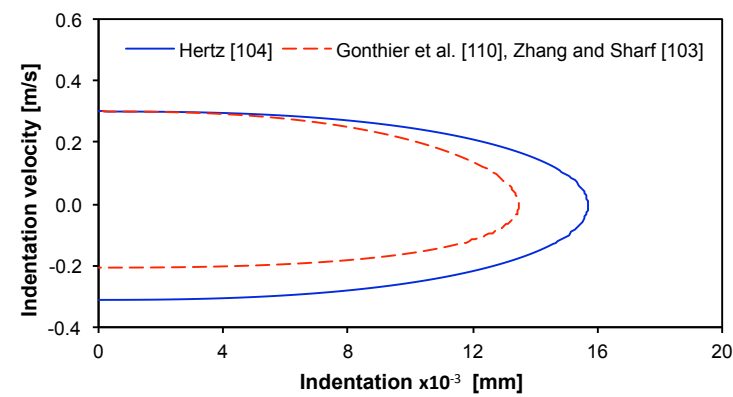

(e)

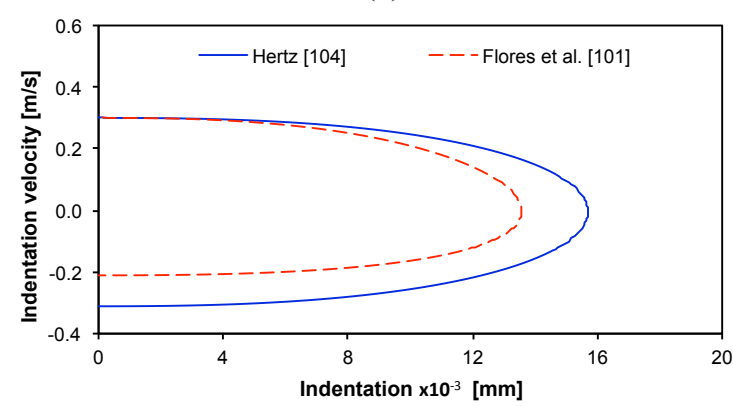

(g)

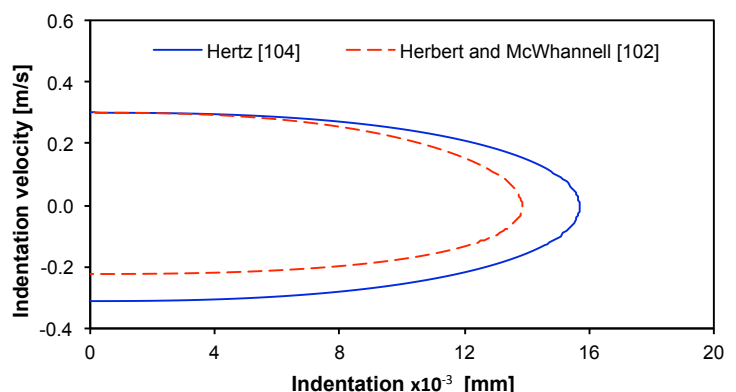

(b)

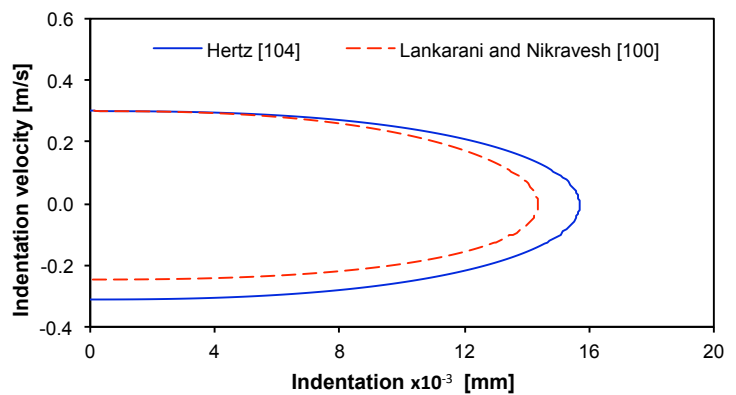

(d)

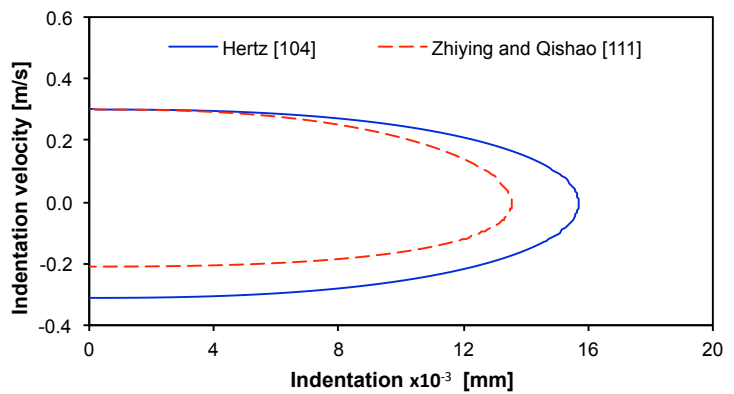

(f)

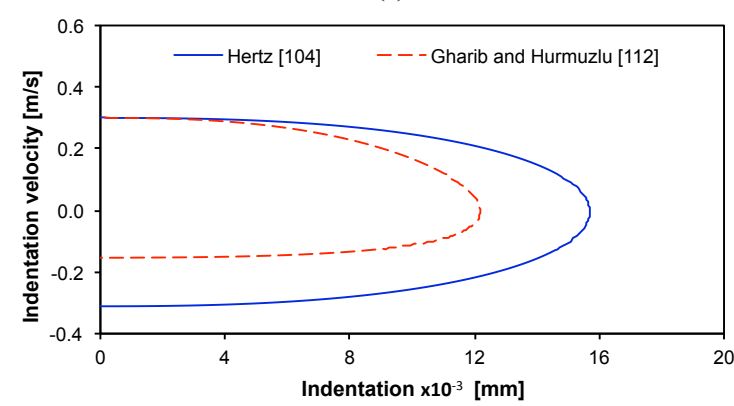

(h)

Fig. 4 Phase portraits for different contact force models for a direct-central impact of two spheres: (a) Hunt and Crossley, Marefka and Orin; (b) Herbert and McWhannell; (c) Lee and Wang; (d) Lankarani and Nikravesh; (e) Gonthier et al., Zhang and Sharf; (f) Zhiying and Qishao; (g) Flores et al.; (h) Gharib and Hurmuzlu.

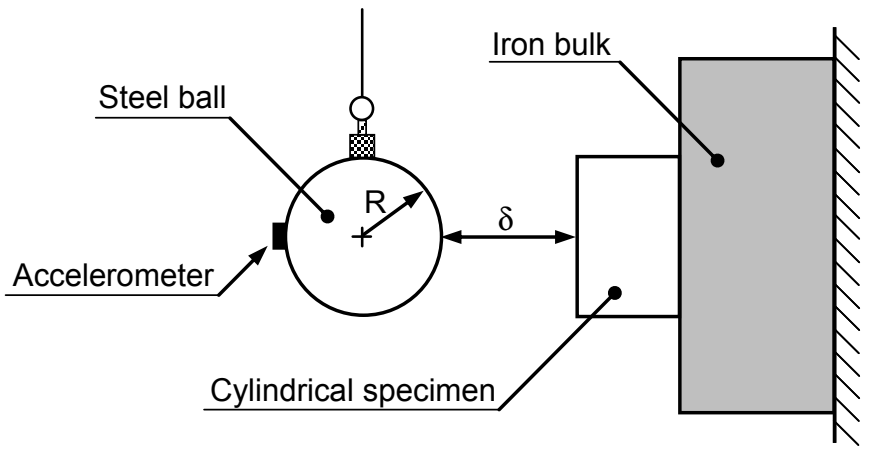

Fig. 5 Impact between a steel ball and a cylindrical specimen \{Adapted from [16]\}. 


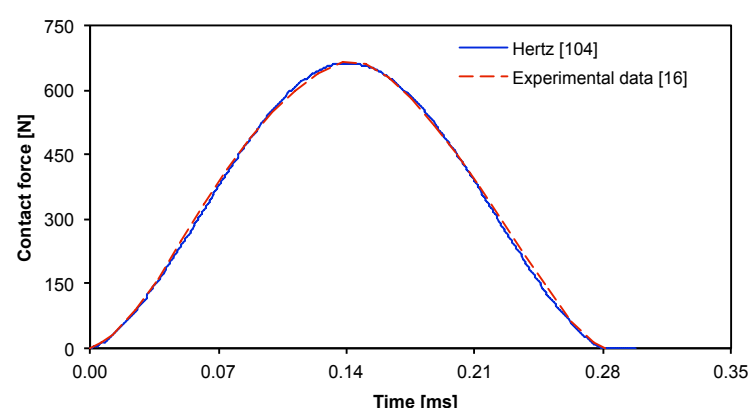

(a)

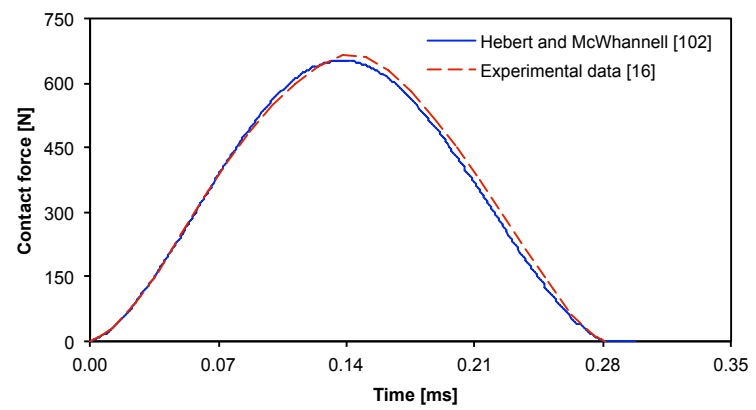

(c)

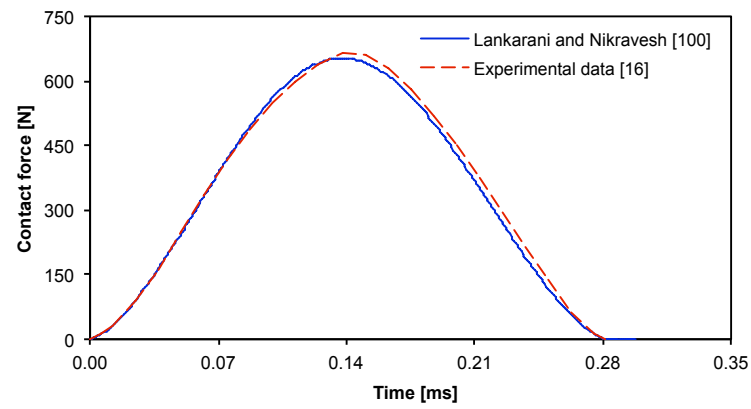

(e)

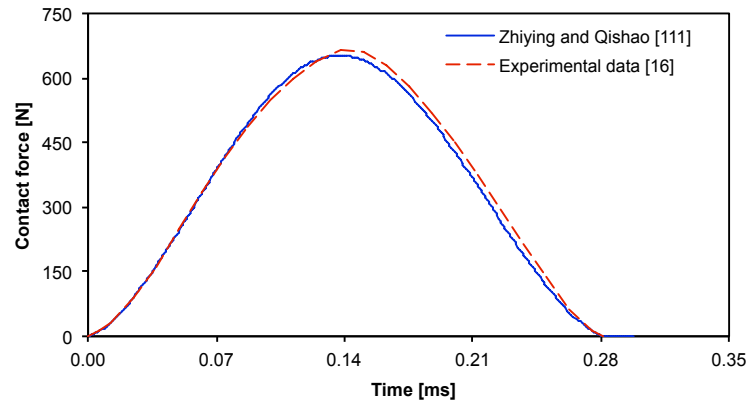

(g)

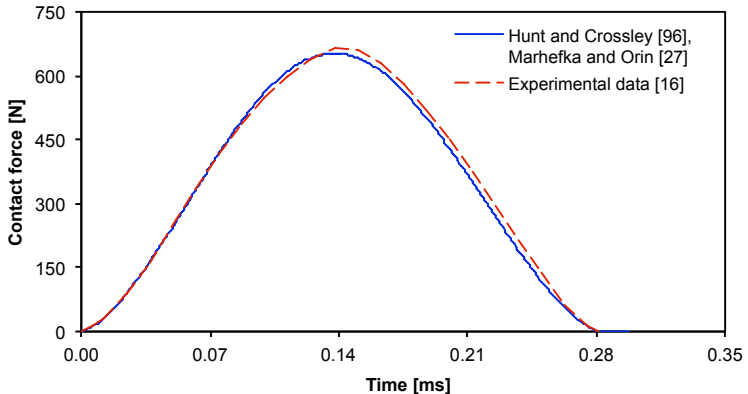

(b)

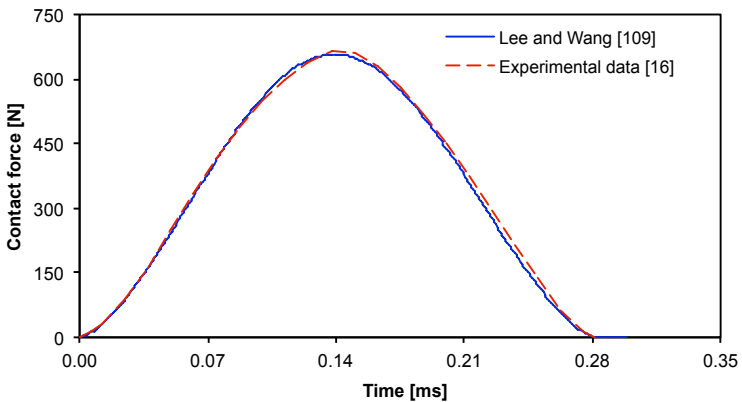

(d)

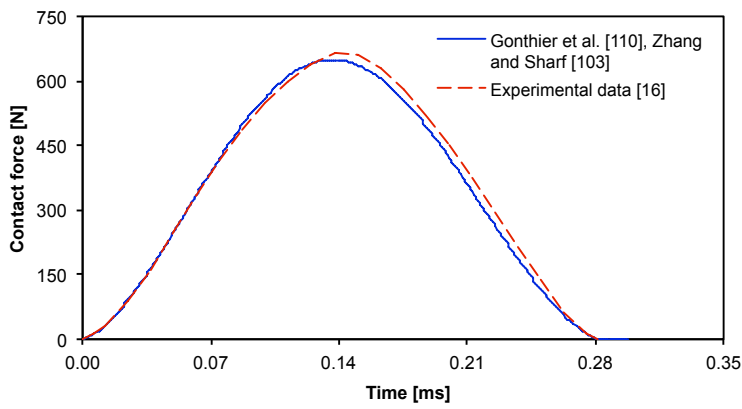

(f)

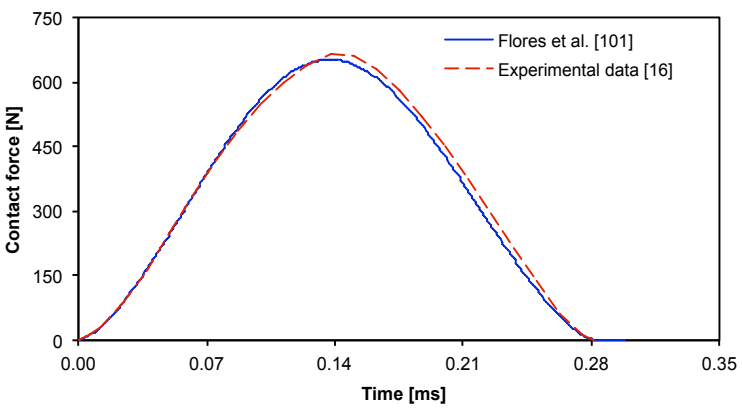

(h)

Fig. 6 Comparison of the contact force time histories for specimen C1, impact velocity of $0.094 \mathrm{~m} / \mathrm{s}$ and eight different contact force models: (a) Hertz; (b) Hunt and Crossley, Marefka and Orin; (c) Herbert and McWhannell; (d) Lee and Wang; (e) Lankarani and Nikravesh; (f) Gonthier et al., Zhang and Sharf; (g) Zhiying and Qishao; (h) Flores et al. 


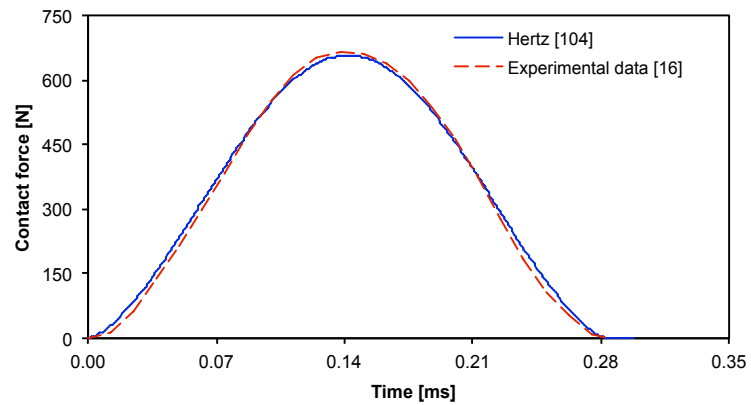

(a)

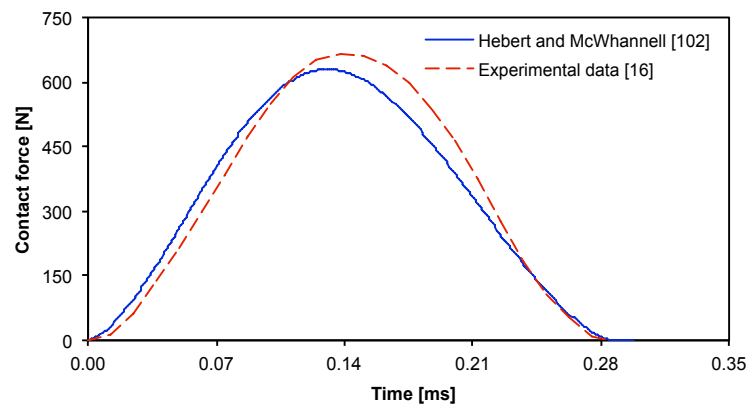

(c)

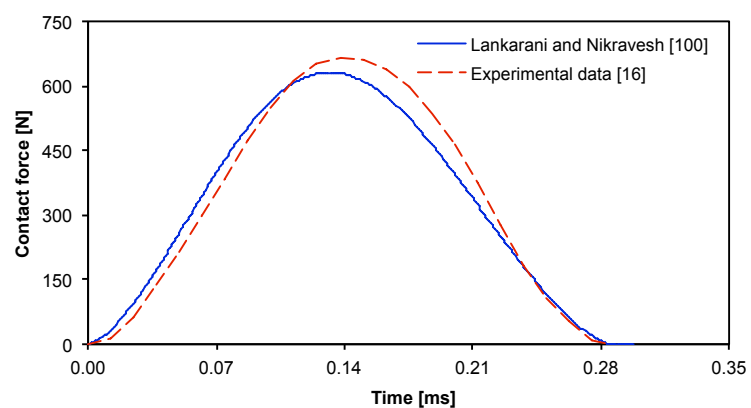

(e)

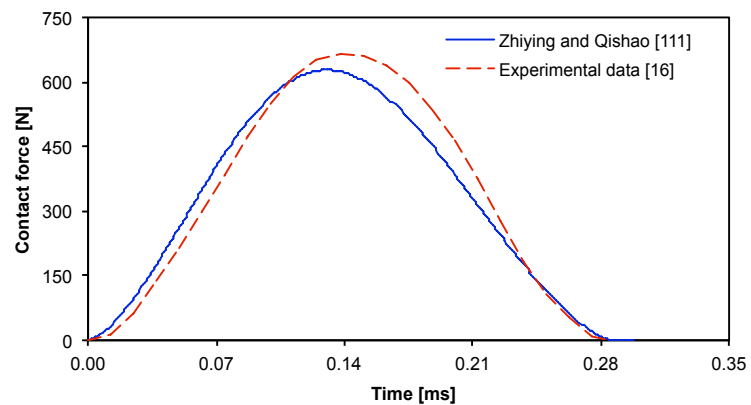

(g)

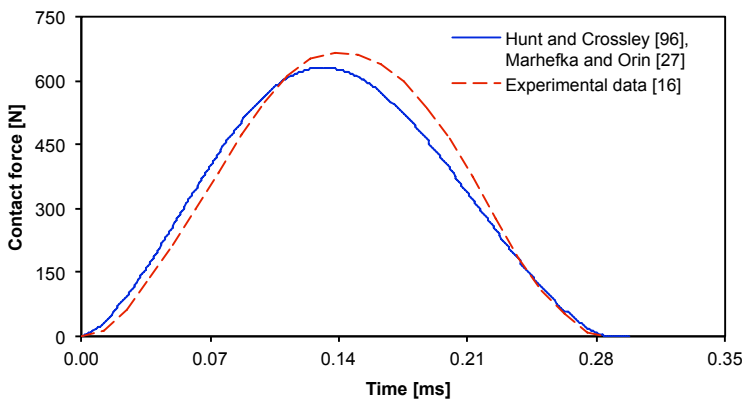

(b)

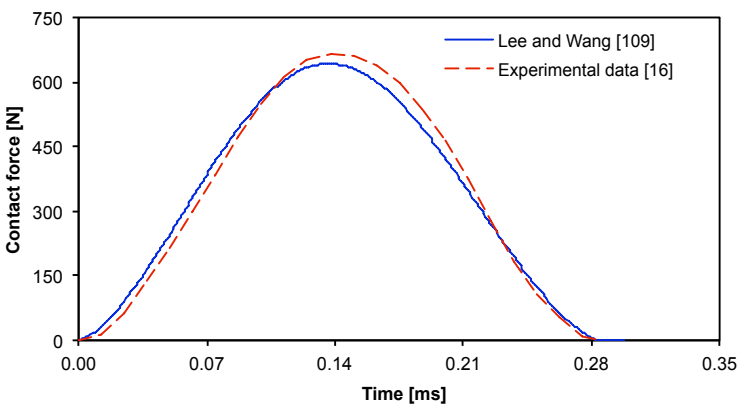

(d)

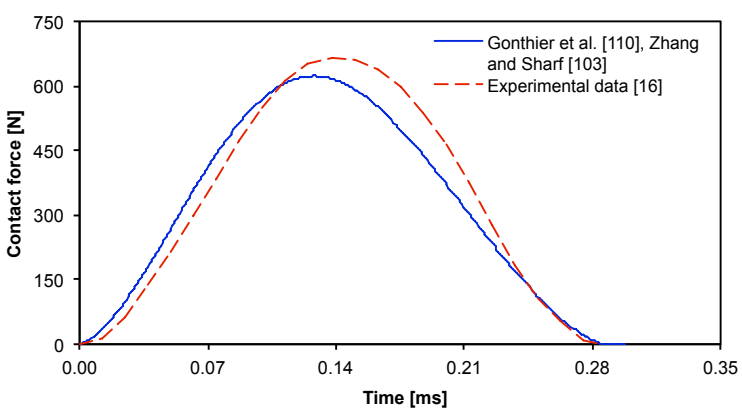

(f)

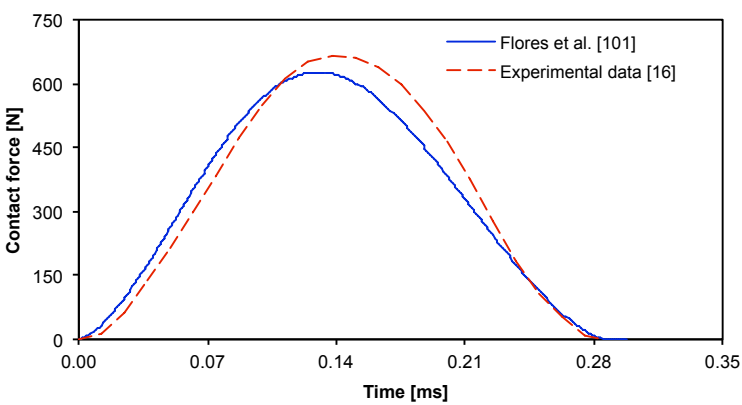

(h)

Fig. 7 Comparison of the contact force time histories for specimen C2, impact velocity of $0.094 \mathrm{~m} / \mathrm{s}$ and eight different contact force models: (a) Hertz; (b) Hunt and Crossley, Marefka and Orin; (c) Herbert and McWhannell; (d) Lee and Wang; (e) Lankarani and Nikravesh; (f) Gonthier et al., Zhang and Sharf; (g) Zhiying and Qishao; (h) Flores et al. 


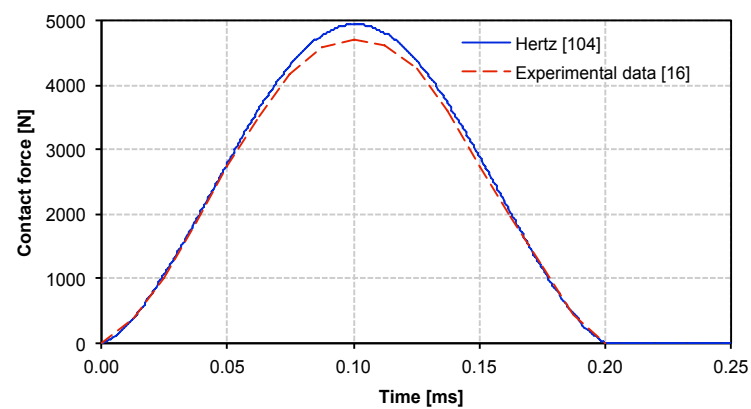

(a)

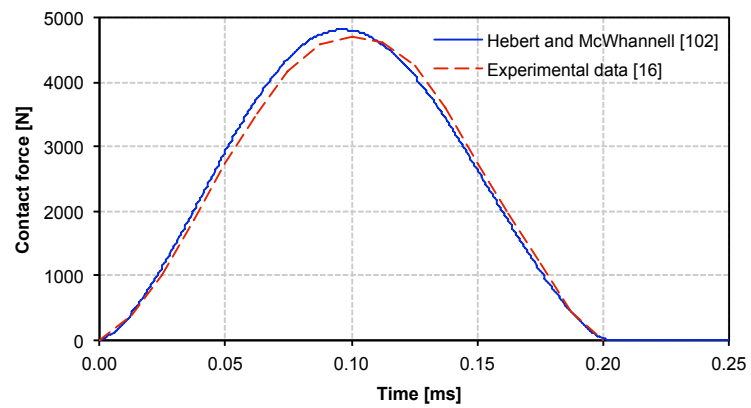

(c)

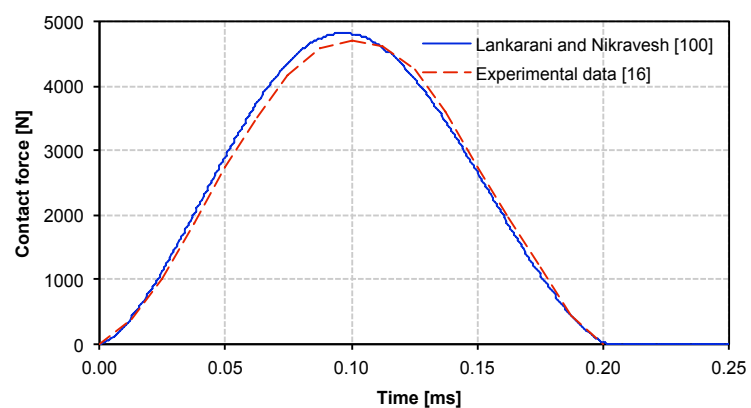

(e)

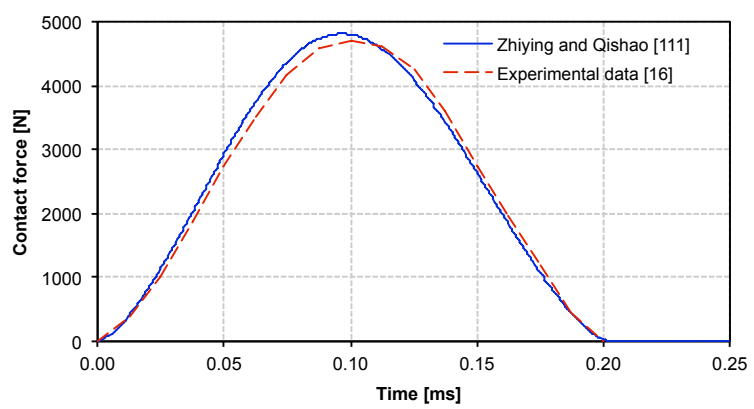

(g)

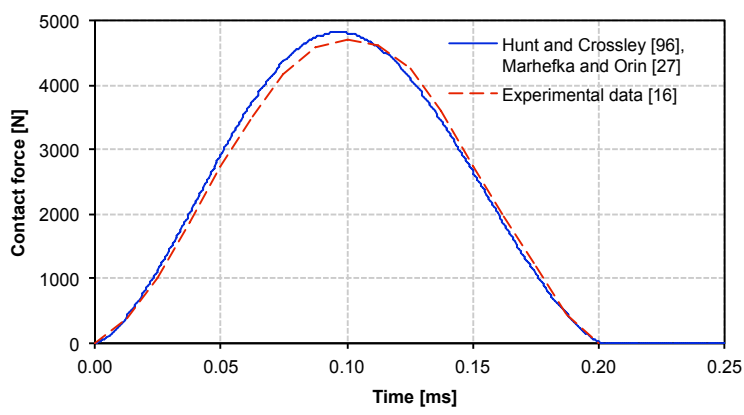

(b)

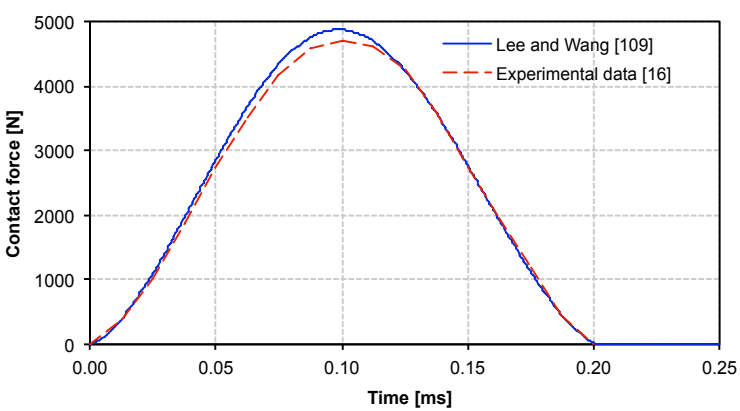

(d)

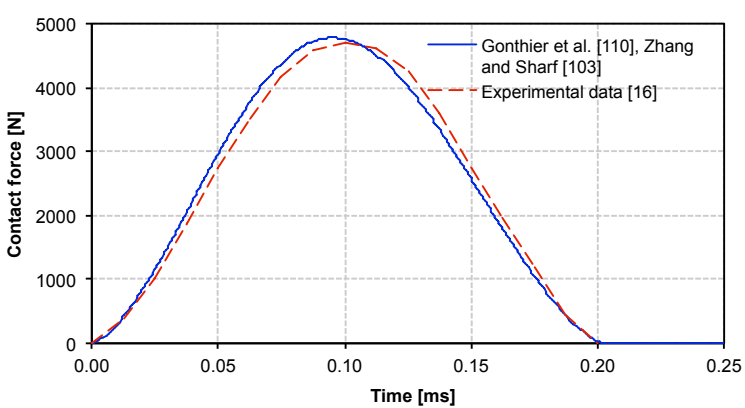

(f)

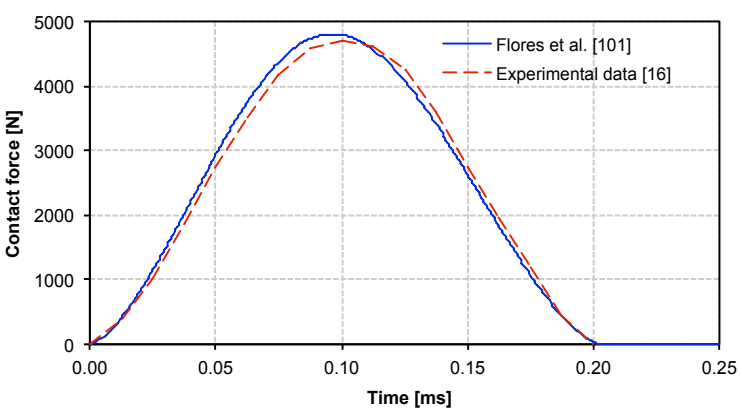

(h)

Fig. 8 Comparison of the contact force time histories for specimen $\mathrm{C} 1$, impact velocity of $0.5 \mathrm{~m} / \mathrm{s}$ and eight different contact force models: (a) Hertz; (b) Hunt and Crossley, Marefka and Orin; (c) Herbert and McWhannell; (d) Lee and Wang; (e) Lankarani and Nikravesh; (f) Gonthier et al., Zhang and Sharf; (g) Zhiying and Qishao; (h) Flores et al. 


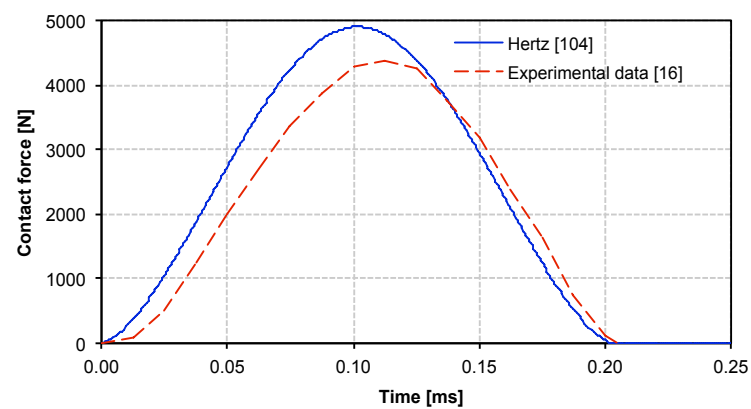

(a)

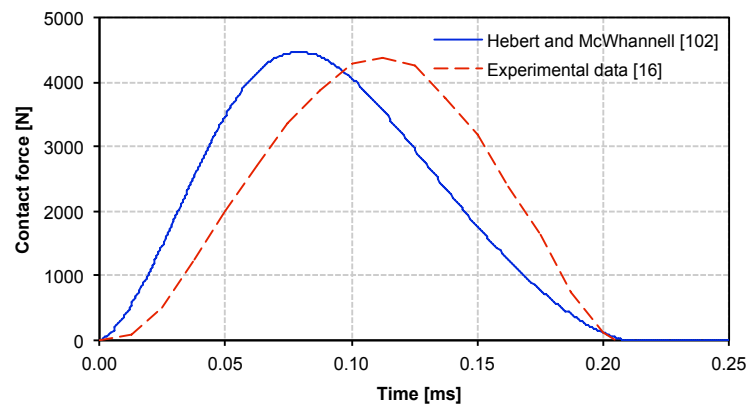

(c)

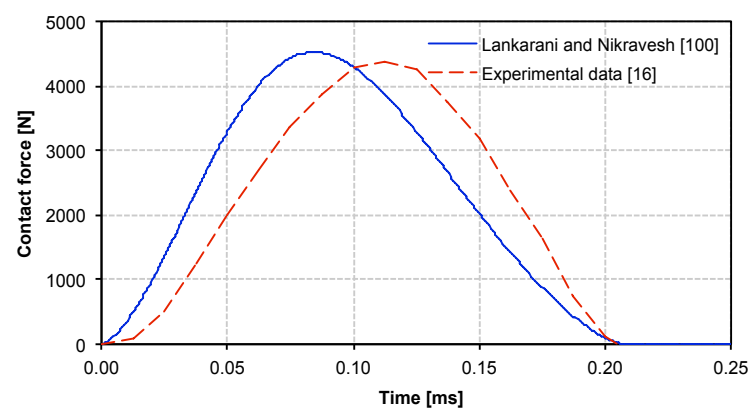

(e)

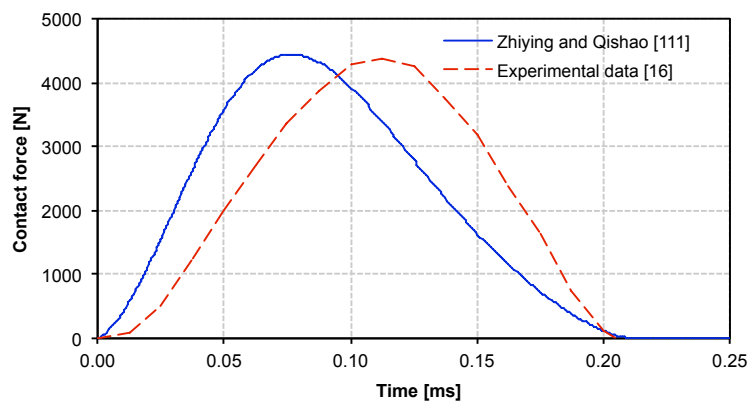

(g)

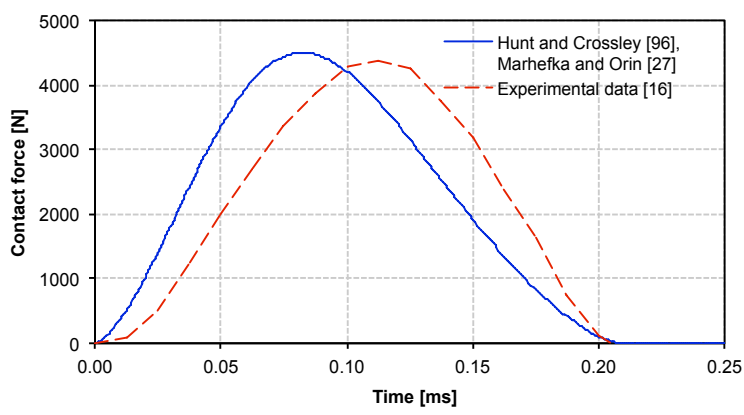

(b)

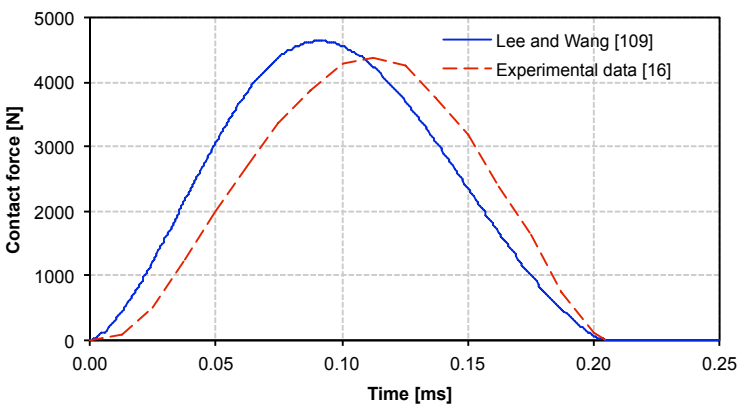

(d)

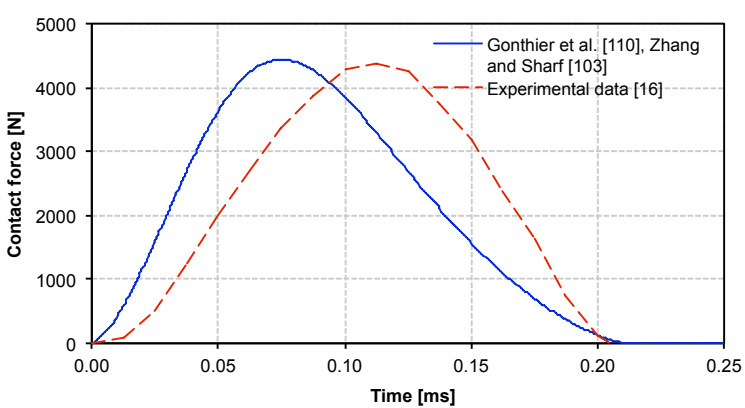

(f)

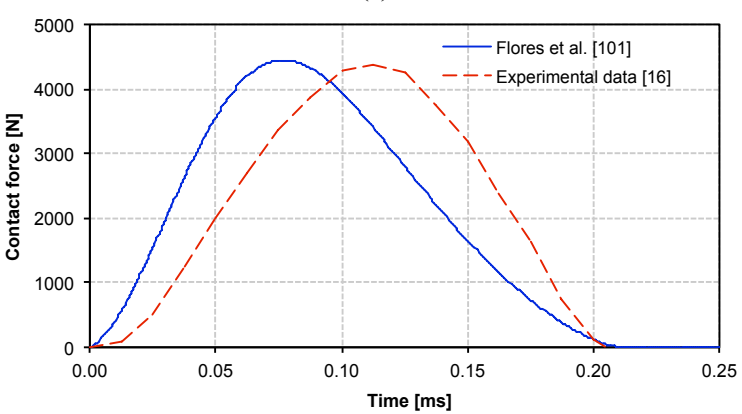

(h)

Fig. 9 Comparison of the contact force time histories for specimen $\mathrm{C} 2$, impact velocity of $0.5 \mathrm{~m} / \mathrm{s}$ and eight different contact force models: (a) Hertz; (b) Hunt and Crossley, Marefka and Orin; (c) Herbert and McWhannell; (d) Lee and Wang; (e) Lankarani and Nikravesh; (f) Gonthier et al., Zhang and Sharf; (g) Zhiying and Qishao; (h) Flores et al. 


\section{List of tables}

Table 1 Hysteresis damping factors for different viscoelastic models, in Eq. (1).

\begin{tabular}{|c|c|c|c|c|}
\hline Contact force model & Constitutive law & $n$ & $m$ & $\chi$ \\
\hline Hertz [104] & $f=K \delta^{\frac{3}{2}}$ & $3 / 2$ & - & - \\
\hline Anagnostopoulos [105] & $f=K \delta+\chi \delta \dot{\delta}$ & 1 & 1 & $\chi=2 \frac{-\ln c_{r}}{\sqrt{\pi^{2}+\left(\ln c_{r}\right)^{2}}} \sqrt{K m_{\text {eff }}}$ \\
\hline $\begin{array}{l}\text { Ristow [106] } \\
\text { Shäfer et al. [107] }\end{array}$ & $f=K \delta^{\frac{3}{2}}+\chi \delta \dot{\delta}$ & $3 / 2$ & 1 & Empirical \\
\hline Lee and Herrmann [108] & $f=K \delta^{\frac{3}{2}}+m_{e f f} \chi \delta \dot{\delta}$ & $3 / 2$ & 1 & Empirical \\
\hline $\begin{array}{l}\text { Hunt and Crossley [96] } \\
\text { Marefka and Orin [27] }\end{array}$ & $f=K \delta^{\frac{3}{2}}+\chi \delta^{\frac{3}{2}} \dot{\delta}$ & $3 / 2$ & $3 / 2$ & $\chi=\frac{3\left(1-c_{r}\right)}{2} \frac{K}{\dot{\delta}^{(-)}}$ \\
\hline Herbert and McWhannell [102] & $f=K \delta^{\frac{3}{2}}+\chi \delta^{\frac{3}{2}} \dot{\delta}$ & $3 / 2$ & $3 / 2$ & $\chi=\frac{6\left(1-c_{r}\right)}{\left[\left(2 c_{r}-1\right)^{2}+3\right]} \frac{K}{\dot{\delta}^{(-)}}$ \\
\hline Lee and Wang [109] & $f=K \delta^{\frac{3}{2}}+\chi \delta^{\frac{3}{2}} \dot{\delta}$ & $3 / 2$ & $3 / 2$ & $\chi=\frac{3\left(1-c_{r}\right)}{4} \frac{K}{\dot{\delta}^{(-)}}$ \\
\hline Lankarani and Nikravesh [100] & $f=K \delta^{\frac{3}{2}}+\chi \delta^{\frac{3}{2}} \dot{\delta}$ & $3 / 2$ & $3 / 2$ & $\chi=\frac{3\left(1-c_{r}^{2}\right)}{4} \frac{K}{\dot{\delta}^{(-)}}$ \\
\hline $\begin{array}{l}\text { Gonthier et al. [110] } \\
\text { Zhang and Sharf [103] }\end{array}$ & $f=K \delta^{\frac{3}{2}}+\chi \delta^{\frac{3}{2}} \dot{\delta}$ & $3 / 2$ & $3 / 2$ & $\chi \approx \frac{1-c_{r}^{2}}{c_{r}} \frac{K}{\dot{\delta}^{(-)}}$ \\
\hline Zhiying and Qishao [111] & $f=K \delta^{\frac{3}{2}}+\chi \delta^{\frac{3}{2}} \dot{\delta}$ & $3 / 2$ & $3 / 2$ & $\chi=\frac{3\left(1-c_{r}^{2}\right) e^{2\left(1-c_{r}\right)}}{4} \frac{K}{\dot{\delta}^{(-)}}$ \\
\hline Flores et al. [101] & $f=K \delta^{\frac{3}{2}}+\chi \delta^{\frac{3}{2}} \dot{\delta}$ & $3 / 2$ & $3 / 2$ & $\chi=\frac{8\left(1-c_{r}\right)}{5 c_{r}} \frac{K}{\dot{\delta}^{(-)}}$ \\
\hline Gharib and Hurmuzlu [112] & $f=K \delta^{\frac{3}{2}}+\chi \delta^{\frac{3}{2}} \dot{\delta}$ & $3 / 2$ & $3 / 2$ & $\chi=\frac{1}{c_{r}} \frac{K}{\dot{\delta}^{(-)}}$ \\
\hline $\begin{array}{l}\text { Kuwabara and Kono [113] } \\
\text { Brilliantov et al. }[114,115]\end{array}$ & $f=K \delta^{\frac{3}{2}}+\chi \delta^{\frac{1}{2}} \dot{\delta}$ & $3 / 2$ & $1 / 2$ & $\chi=\frac{K}{3} \frac{\left(3 \eta_{2}-\eta_{1}\right)^{2}}{3 \eta_{2}+2 \eta_{1}} \frac{(1-v)(1-2 v)}{E v^{2}}$ \\
\hline Tsuji et al. [116] & $f=K \delta^{\frac{3}{2}}+\chi \delta^{\frac{1}{4}} \dot{\delta}$ & $3 / 2$ & $1 / 4$ & $\chi=\alpha \sqrt{K m_{e f f}}$ \\
\hline Jankowski [117] & $\begin{array}{l}f=K \delta^{\frac{3}{2}}+\chi \delta \dot{\delta},(\dot{\delta}>0) \\
f=K \delta^{\frac{3}{2}},(\dot{\delta}<0)\end{array}$ & $3 / 2$ & 1 & $\chi=2 \frac{9 \sqrt{5}}{2} \frac{1-c_{r}^{2}}{c_{r}\left[c_{r}(9 \pi-16)+16\right]} \sqrt{K \delta^{\frac{1}{2}} m_{e f f}}$ \\
\hline $\begin{array}{l}\text { Bordbar and Hyppänen [118] } \\
\text { Schwager and Poschel [119] }\end{array}$ & $f=K \delta^{\frac{3}{2}}+\chi \delta^{0.65} \dot{\delta}$ & $3 / 2$ & 0.65 & Empirical \\
\hline
\end{tabular}

Table 2 Properties of the contacting bodies utilized in the present work \{Adapted from [16]\}.

\begin{tabular}{|c|c|c|c|}
\hline Contact part & $\begin{array}{c}\text { Young's modulus } \\
{[\mathrm{GPa}]}\end{array}$ & Poisson's ratio & $\begin{array}{c}\text { Contact force of } \\
\text { yield }[\mathrm{N}]\end{array}$ \\
\hline Steel ball & 210 & 0.30 & - \\
\hline Specimen C1 & 213 & 0.29 & 6674 \\
\hline Specimen C2 & 205 & 0.29 & 42 \\
\hline
\end{tabular}


Table 3 Generalized contact stiffness and coefficient of restitution \{Adapted from [16]\}.

\begin{tabular}{|c|c|c|}
\hline Contact part & $\begin{array}{c}\text { Contact stiffness } \\
{\left[\mathrm{N} / \mathrm{m}^{3 / 2}\right]}\end{array}$ & $\begin{array}{c}\text { Coefficient of } \\
\text { restitution }\end{array}$ \\
\hline Specimen C1 $(0.094 \mathrm{~m} / \mathrm{s})$ & $2.46 \times 10^{10}$ & 0.974 \\
\hline Specimen C1 $(0.500 \mathrm{~m} / \mathrm{s})$ & $2.46 \times 10^{10}$ & 0.955 \\
\hline Specimen C2 $(0.094 \mathrm{~m} / \mathrm{s})$ & $2.41 \times 10^{10}$ & 0.917 \\
\hline Specimen C2 $(0.500 \mathrm{~m} / \mathrm{s})$ & $2.41 \times 10^{10}$ & 0.757 \\
\hline
\end{tabular}

Table 4 Global results obtained in terms of maximum contact force and corresponding percentage error.

\begin{tabular}{|c|c|c|c|c|c|c|c|c|}
\hline \multirow{3}{*}{$\begin{array}{l}\text { Contact force } \\
\text { model }\end{array}$} & \multicolumn{2}{|c|}{ Specimen C1 } & \multicolumn{2}{|c|}{ Specimen C1 } & \multicolumn{2}{|c|}{ Specimen C2 } & \multicolumn{2}{|c|}{ Specimen C2 } \\
\hline & \multicolumn{2}{|l|}{$0.094 \mathrm{~m} / \mathrm{s}$} & \multicolumn{2}{|l|}{$0.500 \mathrm{~m} / \mathrm{s}$} & \multicolumn{2}{|c|}{$0.094 \mathrm{~m} / \mathrm{s}$} & \multicolumn{2}{|c|}{$0.500 \mathrm{~m} / \mathrm{s}$} \\
\hline & $\mathrm{F}_{\max }[\mathrm{N}]$ & Error [\%] & $\mathrm{F}_{\max }[\mathrm{N}]$ & Error $[\%]$ & $\mathrm{F}_{\max }[\mathrm{N}]$ & Error $[\%]$ & $\mathrm{F}_{\max }[\mathrm{N}]$ & Error $[\%]$ \\
\hline Experimental [16] & 663.0 & - & 4709.6 & - & 660.2 & - & 4364.6 & - \\
\hline Hertz [104] & 662.5 & -0.1 & 4937.8 & 4.8 & 657.5 & -0.4 & 4899.9 & 12.3 \\
\hline $\begin{array}{l}\text { Hunt and Crossley [96], } \\
\text { Marhefka and Orin [27] }\end{array}$ & 652.7 & -1.6 & 4817.6 & 2.3 & 630.6 & -4.5 & 4496.4 & 3.0 \\
\hline Herbert and McWhannell [102] & 652.4 & -1.6 & 4812.8 & 2.2 & 628.9 & -4.7 & 4464.1 & 2.3 \\
\hline Lee and Wang [109] & 657.4 & -0.8 & 4874.3 & 3.5 & 642.6 & -2.7 & 4633.5 & 6.2 \\
\hline Lankarani and Nikravesh [100] & 652.8 & -1.5 & 4820.0 & 2.3 & 631.5 & -4.3 & 4522.3 & 3.6 \\
\hline $\begin{array}{l}\text { Gonthier et al. [110], Zhang } \\
\text { and Sharf [103] }\end{array}$ & 649.5 & -2.0 & 4780.2 & 1.5 & 622.9 & -5.7 & 4436.0 & 1.6 \\
\hline Zhying and Qishao [111] & 652.3 & -1.6 & 4810.1 & 2.1 & 627.8 & -4.9 & 4444.0 & 1.8 \\
\hline Flores et al. [101] & 651.8 & -1.7 & 4805.2 & 2.0 & 627.2 & -5.0 & 4445.5 & 1.9 \\
\hline
\end{tabular}

